TI-IE UNIVERSITY OF MANITOBA

AN ANALYTIC BASIS FOR HEADGFAR DESIGN

BY

PHIIIP CAPTER

\begin{abstract}
A THESIS
SUBMITIED TO TFE FACULITY OF GRADUATE STUDIES

IN PARTIAI FULFIIMENT OF THE REOUIREMENTS FOR THE DEGREE

OF MASTER OF SCIFNCE
\end{abstract}

DEPARTMENT OF PREVENTTIVE NENTAL SCIENCE

WINNIPEG, MANITOBA

JUY, 1981 


\section{AN ANALYTIC BASIS FOR HEADGEAR DESIGN}

\section{BY}

\section{PHILIP CARTER}

A thesis submitted to the Faculty of Graduate Studies of the University of Manitoba in partial fulfillment of the requirements of the degree of

\section{MASTER OF SCIENCE}

(c) 1981

Permission has been granted to the LIBRARY OF THE UNIVERSITY OF MANITOBA to lend or sell copies of this thesis, to the NATIONAL LIBRARY OF CANADA to microfilm this thesis and to lend or sell copies of the film, and UNIVERSITY MICROFILMS to publish an abstract of this thesis.

The author reserves other publication rights, and neither the thesis nor extensive extracts from it may be printed or otherwise reproduced without the author's written permission. 


\title{
Abstract
}

\begin{abstract}
Analysis of the three dimensional force/moment system required during headgear therapy is presented and vector algebra is used to delineate the mechanical compatibilities. This approach clearly shows that the forces required for translations cannot generally provide the moments needed for rotations without producing clinically undesirable side effects. Two methods of avoiding these effects are discussed. These are:
\end{abstract}

(i) sequencing of treatment so that mechanically compatible force/moment systems are applied in several distinct phases of treatment, and

(ii) the use of couples to provide the required moment.

The design of a headcap suitable for providing the couples required in the second of these methods is discussed.

Clinically, both methods provide a number of advantages over those previously used. One such advantage is that the orthodontist must logically approach and quantify the force/moment system required. If properly applied, both methods ensure that no undersirable side effects are produced. Another important advantage is that of making it easy for the orthodontist to monitor and correct tooth movement during the headgear phase of treatment.

A solution to the asymmetric headgear problem is given in the form of a buttressed neck strap. It is shown that where cervically directed forces are indicated such a strap permits differential dis- 
talization without producing the undesired lateral force common to all other proposed unilateral headgear solutions.

In testing the general and particular methods proposed for headgear design, a computer program was developed and used. A brief outline of the program and some results illustrating its use were given. In addition to clearly indicating the compatible forces and moments, results of the previous program are used with the pertinent patient data to draw the main features of the outer bow. A full scale drawing may be used as a template for face bow construction. The template drawing part of the program is for headgear design involving a cervical strap only, though extension to full headcap cases would not be difficult. 


\section{Acknowledgements}

The completion of this thesis represents the combined efforts of a number of individuals to whom I would like to express formally my sincerest appreciation.

Professor Ken McLachlan, Department of Civil Engineering, provided throughout this endeavour far more than supervision and hard work. His holistic approach to education and research led this writer to a new awareness and appreciation of the joy of science.

My thanks to Dr. A.T. Storey and Dr. D. Smith, members of my committee, for their suggestions and help in writing of this thesis.

Fellow students Sam Chiang and Elli Roehm, as well as the orthodontic graudates of 1980 and 1982, helped make this educational process a rewarding experience.

The preparation and typing of this document is a credit to the patience and interpretive powers of Joanne Gilbert. 
TABIE OF CONTENTS

CHAPTER

PAGE

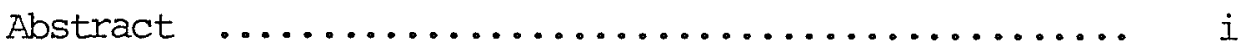

Acknowledgements $\ldots \ldots \ldots \ldots \ldots \ldots \ldots \ldots \ldots \ldots \ldots$ ii

Table of Contents $\ldots \ldots \ldots \ldots \ldots \ldots \ldots \ldots \ldots$ iv

List of Figures $\ldots \ldots \ldots \ldots \ldots \ldots \ldots \ldots \ldots \ldots \ldots \ldots$ vi

List of Examples $\ldots \ldots \ldots \ldots \ldots \ldots \ldots \ldots \ldots \ldots \ldots$ vii

$1 \quad$ Review of Literature

1.1 Introduction $\ldots \ldots \ldots \ldots \ldots \ldots \ldots \ldots \ldots \ldots \ldots$

1.2 Clinical Usage of Headgear System $\ldots \ldots \ldots \ldots .3$

1.3 Unilateral Mechanics $\ldots \ldots \ldots \ldots \ldots \ldots \ldots \ldots \ldots$

1.4 Direction of Force $\ldots \ldots \ldots \ldots \ldots \ldots \ldots \ldots \ldots \ldots$

1.5 Rigid Body Assumption $\ldots \ldots \ldots \ldots \ldots \ldots \ldots \ldots$

1.6 Summary $\ldots \ldots \ldots \ldots \ldots \ldots \ldots \ldots \ldots \ldots \ldots \ldots \ldots$

2 Statement of Problem $\ldots \ldots \ldots \ldots \ldots \ldots \ldots \ldots \ldots \ldots \ldots$

$3 \quad$ Materials and Methods

3.1 Mechanical Principles $\ldots \ldots \ldots \ldots \ldots \ldots \ldots . . .20$

3.2 Computer Application $\ldots \ldots \ldots \ldots \ldots \ldots \ldots . .29$

$4 \quad$ Results

4.1 Vector Consequences $\ldots \ldots \ldots \ldots \ldots \ldots \ldots \ldots \ldots . \ldots . \ldots$

4.2 Computer Partitioning $\ldots \ldots \ldots \ldots \ldots \ldots \ldots . \ldots 34$

4.3 Computer Aided Design $\ldots \ldots \ldots \ldots \ldots \ldots \ldots . \ldots 42$

5 Discussion of Results

5.1 Introduction $\ldots \ldots \ldots \ldots \ldots \ldots \ldots \ldots \ldots \ldots$ 
5.2 Sequencing $\ldots \ldots \ldots \ldots \ldots \ldots \ldots \ldots \ldots \ldots \ldots$

5.3 Force Sharing $\ldots \ldots \ldots \ldots \ldots \ldots \ldots \ldots \ldots \ldots .60$

5.4 Couples Generated by Force Dairs ........ 51

5.5 Replacement of $\bar{F}$ by Two Forces $\ldots \ldots \ldots \ldots \ldots$

5.6 Buttressed Neck Strap $\ldots \ldots \ldots \ldots \ldots \ldots \ldots \ldots$

5.7 Treatment Goals $\ldots \ldots \ldots \ldots \ldots \ldots \ldots \ldots \ldots \ldots .58$ 
IIST OF FIGLRES

Figures

Page

3.1 Definition of axis system $\ldots \ldots \ldots \ldots \ldots \ldots \ldots \ldots \ldots \ldots \ldots$

3.2 Generation of a moment about the origin by a force "F" acting at point "p"

3.3 Equivalent force-couple system $\ldots \ldots \ldots \ldots \ldots \ldots \ldots \ldots \ldots$

4.1 Proposed force system appended to pertinent patient

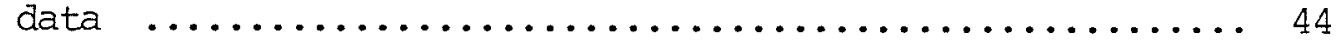

4.2 Plan view of buttressed neck strap $\ldots \ldots \ldots \ldots \ldots \ldots \ldots$

4.3 Elevation showing line of force with cervical neck

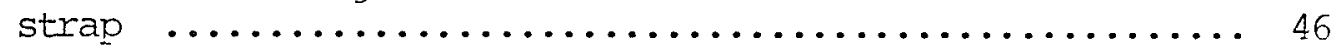

5.1 A proposed headgear to generate the required moments by

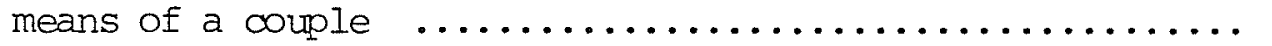

5.2 Plan view of mechanics using a couple for moment generation 
4.1 Force/moment system recuired for differential

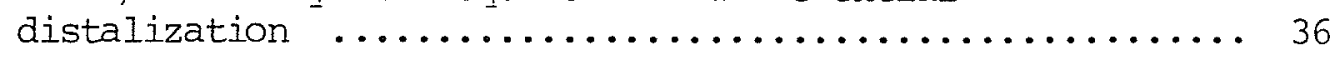

4.2 Force/moment system recuired for distalization and differential extrusion. Partitioning at $F_{X}-M_{X}$ indicates sequencing must be used

4.3 Force/moment system recuiring one force but tho moments. $M_{y}$ must be produced by a couple $\ldots \ldots \ldots \ldots \ldots . . . .38$

4.4 Required force/moment system used in section $4.1 \quad \ldots \ldots \ldots 39$

4.5 The most complex force/moment system requiring three forces and three moments

4.6 Recuired force/moment system has two forces but three moments. $F_{x}$ used to generate both $M_{y}$ and $M_{z} \quad \ldots . .41$ 


\section{Review of Literature}

\subsection{Introduction}

The use of extra-oral anchorage in the clinical practice of orthodontics has shown marked fluctuations over the past 150 years. Many modifications to, and applications of, the basic system have been made, but the underlying mechanical principles remain the same: forces equal in magnitude but opposite in direction are applied to two bodies, one, a relatively immovable cranium and/or neck, the other, a much smaller less resistant body, namely, the maxillary-dental complex. This complex may be one molar on each side or a group of teeth on each side. For clarity, in this thesis the teeth on each side will be referred to as a buccal segment and these two segments will be assumed to be mechanically connected to form a rigid body. It is further assumed that the forces applied to the buccal segments induce stresses that are adequate for tooth movement. The mechanism whereby forces cause quasi-permanent changes in tooth position is yet to be fully elucidated as is the functional relationship between force, and the rate of tooth movement. It is quite safe to say, however, that remodelling of bone occurs in response to the pressure applied and that unless this force system is fully understood by the clinician, there is not much hope of attaining desired tooth movement. The unequivocal resolution of the mechanical forces applied with extra-oral anchorage has not yet been shown, and therefore it is not surprising that controversy exists concerning the efficacy of such treatment. 
This is especially true of the unilateral, or asymmetric headgear, with which the clinician attempts to exert a greater distalization force on one buccal segment relative to the other. 


\subsection{Clinical Usage of Headgear Systems}

The history of modern extra-oral anchorage goes back about one hundred years to the work of Kingsley. It was reported (Latimer 1886) that Kingsley fabricated a gold band or plate resting against the labial surface of the anterior teeth. Heavy elastic straps connected this tooth borne support to a skull cap, fabricated of leather or cloth. Thus a distalizing pressure was introduced on the anterior portion of the dentition forcing the incisors up and back. This treatment remained for many years as the only successful method of treating severe Class II division I malocclusions. Kingsley also introduced the concept of applying a force to the entire maxilla, constructing a cast framework over the molars and bicuspids with an outer bow extending to a point opposite the first molar (Kingsley, Fig. 6, 1892). Angle (1889) described his extra-oral appliance which had the special feature of a ball and socket attachment between inner and outer bows. This would permit freedom from moment constraint in the three planes of space. This idea was not followed up at the time, as Angle's ideas were changing, and extra-oral anchorage was largely replaced by inter-arch elastics.

Case (1921), however, continued to use extra-oral anchorage and delineated three applications for its use:

1) to direct a distalizing force against the anterior dentition in Class II extraction cases,

2) to produce extrusive force especially on the lower incisors in 
open bite cases and

3) to produce distal force on bicuspids and molars.

He developed the first cervical anchor strap which, when combined with a skull cap allowed a direction of force to be either above or below the ear. This permitted variability in the line of force in the antero-posterior plane.

The widespread use of inter-maxillary elastics did not go unchallenged. Brodie et al. (1938) in a cephalometric study showed that changes were basically restricted to the alveolus and the tendency to relapse was high. The occlusal plane which changed during treatment also relapsed on the discontinuance of elastic therapy. Oppenheim (1944) applied cervical headgear forces to maxillary molars in a Class II case where conventional multi-band therapy was contra-indicated. He was so encouraged by the result he brought his idea to the United States and reported widely on his success. He felt that light forces applied to the molars imparted through the transeptal fibers, a distalizing force to the entire maxilla.

Epstein (1948) looked at twelve Class II cases treated exclusively by extra-oral mechanics. He concluded from cephalometric analysis that some molars were moved distally in the maxilla relative to controls while others seemed unchanged. The correction of the Class II molar relationship however, occurred basically as a result of the downward and forward growth of the mandible relative to the maxilla. Kloehn (1947, 1953) modified the appliance by soldering the inner (dental) bow to the outer (facial) bow, thus making a more rigid 
appliance. His name became widely associated with cervical anchorage, especially for early treatment (Kloehn, 1955).

Analysis of post-treatment records of patients wearing cervical headgear revealed deliterious side effects. These side-effects especially damaging in the Class II division $I$ cases are elaborated in section 1.4. As a result the cervical strap of the 50's and 60's was often replaced by a variable-pull headgear. This system can individualize the line of force and avoid some of the unwanted side effects. 


\subsection{Unilateral Mechanics}

At the same time that this clinical data was being reported, a more detailed study into the force and moment system was being pursued.

A paper given to the Midwest Component of the Angle Society in 1953 by J.P. Baldridge initiated much discussion on the precise definition of the force-moment system involved with the use of headgear. Specifically he reported on the fabrication and use of a unilateral cervical headgear and demonstrated several clinical cases. The solder joint (Baldridge, Fig. 4, 1961) between the inner (dental) arch and the outer (facial) bow was positioned asymmetrically, in a position over the lateral incisor, to the side that required excess distalization. He felt that the offset joint itself would produce an asymmetric force system. No more detailed analysis of forces was given and evidence that such a system produced unilateral forces remained empirical and based on clinical cases. Baldridge shows two, Class II subdivision cases, both with considerable growth potential that were treated to a Class I molar relationship. His treatment consisted of the unilateral headgear attached to only the upper first molars, with full banding instituted upon correction of the buccal relationship. He felt that these unilateral mechanics were especially beneficial in mutilated cases.

Several authors refer to the unpublished works of Block and Boman in 1954 and 1955. Block did analysis and testing of asymmetric sold- 
ered face bows while Boman seems the first to alter the attachment points by the lateral bending of the outer bow. Copies of these papers were not available for consideration in this literature review. In 1958 Haack and Weinstein presented a landmark paper which involved both the engineering and orthodontic disciplines. They calculated the forces applied upon activation of a headgear with an asymmetric outer bow. They assumed that the magnitude of the two forces applied with a cervical neck strap would be equal, as friction between the neck and strap would be nullified over a period of time with movements of the patient's head. The inner and outer bows were assumed to be rigid and lateral forces on the buccal segments equal in magnitude and direction. Haack and Weinstein solved the equilibrium equations to produce a ratio of distalizing forces (left/right) with respect to the total distalizing force. They indicated that one way of altering this ratio of forces is to make the outer bow longer on one side. This produces a resultant force which is not on the mid-sagittal plane, but closer to one molar than the other (Haack and Weinstein, Fig. 2, 1958). If this resultant line of force was located half way between the mid-sagittal plane and the molar, they believed the appropriate unilateral forces would be introduced. If the resultant force intersects the the mid-sagittal plane at a greater angle the authors claim unwanted lateral forces become clinically important. They challenged the asymetric soldered headgear reported by Baldridge (1953) and state that no matter where the rigid attachment is placed (offcenter or not) the forces on the left and right molars will have the 
same distalizing effect. Experiments on models using tension gauges applied at the molars showed no asymmetry of forces with the offset soldered joint. The asymmetric outer bow, however, produced a greater distalizing force on one side. The lateral force which was developed with the asymmetric outer bow could be used in conjunction with expanded or contracted archwires to develop a lateral force on one side of the arch exclusively. This could be an important adjunct in the treatment of true unilateral crossbites of maxillary origin.

Drenker (1959) furthered the ideas and analysis of Haack and Weinstein. His mathematical analysis as applied to the unilateral headgear of Baldridge (offset soldered joint) showed that the design would work only if the rigid attachment was replaced by an offset knife-edge connection; that is, a connection which would allow the outer bow to pivot about the vertical axis. In this case the point of external force application is considered to be the knife-edge itself and the moment to force ratio as applied to the maxilla can be readily determined by the amount of the offset. He claims that it would be impossible to utilize a knife-edge connection in clinical orthodontics but did not further investigate the possibilities.

In fabricating the center-soldered headgear Drenker also suggested altering the rigid outer bow. The lengthening (up to two inches) and outward bending (up to three-quarter inch) on one side of the outer bow was recommended. This amount of adjustment was claimed to be well tolerated by the patient and did not cause the headgear to be dislodged at night. He further recommended the use of heavy 
extra-oral and intra-oral bows to minimize flexibility and the consequent differences in geometry, between passive and active positions. Drenker suggested that friction between the neck strap and back of neck may give rise to unequal forces and, hence, an unknown force system. He equilibrated left and right strap forces by several quick head movements or running a finger between the strap and neck.

Baldridge (1961) reported on intra-oral tests performed on headgears which were of an asymmetric design. He measured the compression of coil springs, compressed against the headgear tube on the first molars when various headgears were used. In this design forces are exerted along the inner bow and no lateral forces are generated. He demonstrated that both lengthening and expanding one side of the outer bow created unilateral forces using both light (454 gm./side) and heavy (908 gm./side) tensional forces in the cervical strap. Even with the solder joint offset $12.7 \mathrm{~mm}$. and high forces (908 gm./side) Baldridge was unable to detect a difference between forces at the left and right molars. This result is in agreement with that expected from force analyses.

Block (Fig. 6, 1962) describes an appliance to obtain unilateral molar repositioning. On the side to be distalized headgear forces are applied to a sliding hook which compresses a coil spring against the molar tube. On the opposite side the forces are applied to a soldered hook on the archwire near the cuspid. Stability is maintained by an acrylic appliance.

The geometry of unilateral cervical headgear was challenged by 
Oosthuizen et al. (1973). In plan they noted that the outward bending of one bow (a traditional method of altering the line of force) does not appreciably alter the line of force and hence does not alter the equality of forces on the buccal segments.

Terlingen (1973) conducted tests on different face bows with three dimensional force transducers. He claimed unilateral forces are generated when an asymmetric solder joint is utilized. Force analysis was also conducted using the asymmetric outer bow. To demonstrate his results a diagram was drawn to show the relationship between the external lines of force and the distalizing forces applied to the buccal segments.

Jacobson (1979) used a mechanical model to test various designs of unilateral mechanics. His device consisted of "frictionless" pulleys supporting weights which indicated loads in lateral and anteroposterior direction. He felt that due to the flexibility of the system under load, mathematical appraisal was almost impossible. He notes that inner bows of .045 inch $(1.14 \mathrm{~mm}$.) or smaller show flaring or splaying at the ends under normal orthodontic loads, unless supported anteriorly by solder or tubing. The center-soldered asymmetric outer bow produced unilateral effects but lateral forces were quite evident. The most effective type of unilateral device according to Jacobsen is the offset pivot type (Jacobson, Fig. 27, 1979). Using relatively rigid outer and inner bows he claims that the device under tension, $16 \mathrm{oz}$. (454 gm.) per side, can produce an asymmetric distalizing force with no measurable side forces. The outer bows pivot 
under load about the vertical axis until a state of moment equilibrium exists (Jacobson, Fig. 28, 1979).

Baldini (1980) notes that there is a considerble discrepancy between the results of his mathematical analysis and the experimental results of Jacobson. Baldini suggests that the mechanical measuring device used by Jacobson has many inherent errors.

Hershey et al. (1981) used force transducers to record distalizing and lateral forces when various types of headgear were tested. They concluded that both the asymmetric outer bow (power arm) type and swivel offset facebow were effective in delivering a clinically significant unilateral distal force (about $75 \%$ of the total distal force). Similar lateral forces were produced with both styles. Mathematical analysis supported these findings.

The unilateral force problem using cervical strap has been analyzed by both mathematical and experimental means and the results tend to be conflicting even when limited to analysis in two dimensions. The quantification of detrimental side effects, the altering or deforming of the outer bows, the validity of using a pivot system, and the problem of defining precisely the wanted force system are substantial points that need to be further investigated. 


\subsection{Direction of Force}

The widespread use of the cervical headgear during the 50 's and early $60^{\prime}$ 's led to certain clinical problems known as the Kloehn reaction (Wieslander, 1963; Schudy, 1965, 1968; Poulton, 1967; Kuhn, 1968; Ricketts, 1960; etc.). The major features of this reaction are;

(1) lack of facial improvement,

(2) relapse of Class II cases,

(3) extrusion and distal crown tipping of the maxillary molars,

(4) clockwise rotation of the mandible,

(5) tipping of the palatal plane,

(6) difficulty in reducing $A N B$ angle,

(7) long and very upright maxillary anterior segment.

It was noted that for each millimeter of molar extrusion the mandibular plane angle increased .75 degrees, and the ANB angle increased .5 degrees (Merrifield and Cross, 1970). In patients with a steep mandibular plane angle, it was noted that there was an increased extrusive component. This resulted in greater detrimental changes. These changes were obviously undersirable for the orthodontic correction of Class II division I malocclusions and cervical anchorage fell from favour. Cephalometric radiographs with the cervical strap in place (Merrifield and Cross, 1970; Worms et al., 1973) showed that the location of the strap at the back of the neck is at the level of the third cervical vertebrae. Therefore the inclination of the line of force 
relative to the occlusal plane is dependent on the position of the outer bows and the cant of the occlusal plane. The perpendicular distance from the line of force to the center of resistance of the buccal segments is dependent on the position of the outer bows. If the outer bow lies in a plane with the inner bow a line of force about 30 degrees below the occlusal plane is generated in most cases (Merrifield and Cross, 1970). Obviously, this angle varies with the type of case; e.g. Class II division 2 cases generally have a low Frankfurt mandibular plane angle which gives rise to a lower than normal angle between the occlusal plane and the line of force provided by a cervical strap. Variable pull headgear may have a line of force somewhere between cervical and highpull (parietal) headgear and, hence, an angle from below to above the occlusal plane can be selected.

The positon of the center of resistance of the first permanent molars, or of the entire maxillary dentition is the point about which constraining forces may be said to act. This is assumed to be at the middle to apical third of the tooth (Greenspan, 1970). Worms et al. (1973) clinically determined the center of resistance of the maxillary first molars to be in the area of their trifurcation. Poulton (1959) looked at the full banded upper arch and decided the center of resistance of the maxillary dentition was at a point lying between the roots of the bicuspids about half way between the cemento-enamel junction and the apex. The exact center of resistance is dependent on a number of variables; the number of teeth banded, the rigidity of the fixation of the teeth, and the size and position of the individual 
teeth (Barton, 1972). Terlingen (1973) suggests that the center of resistance, rather than being fixed, probably varies with the direction of the load. In summary, it seems that a good approximation of the center of resistance of the buccal segment including the bicuspids and the molars would be found (in elevation) near the mesial root of the first permanent molar about half way between the apex and the cemento-enamel junction.

Gould (1957) discussed mechanical principles in relation to headgear. A force through the center of resistance of a body will produce translation of that body while a force not through the center of resistance will not only translate but will rotate the body. The relative amounts of translation and rotation depend on how far the line of force is from the center of resistance. This rotational component (force times perpendicular distance) is known as the moment of the force. He showed how alterations in length and inclination of the outer bow affects the line of force relative to the center of resistance and, hence, the likely movement of the tooth. Oosthuizen et al. (1973) demonstrated the use of cervical headgear with very low outer bow producing little or no extrusive component but a large clockwise moment. Others, Kuhn (1968) and Greenspan (1970) showed a wide variety of outer bows (length and inclination) which in conjunction with low to high anchorage positions produced a variety of force systems which gave combinations of tooth translation and rotation. 


\subsection{Rigid Body Assumption}

The theroretical models proposed by some authors assume rigid body characteristics for the inner-outer bow system. Root (Brandt and Root, 1975) feels that an .045 inch $(1.14 \mathrm{~mm}$.) inner bow and .062 inch ( $1.57 \mathrm{~mm}$.$) outer bow is adequate provided it is strengthened anteri-$ orly. Worms et al. (1973) suggests the use of .072 inch ( $1.83 \mathrm{~mm}$. wire for both the outer and inner bows to more closely approximate rigid body conditions. Since stiffness is proportional to the fourth power of diameter, such increases provide substantial changes in stiffness. If the inner bow (.045 inch or $1.14 \mathrm{~mm}$.) is not strengthened anteriorly, unknown buccal forces will be introduced upon normal clinical loading. Several authors have also commented on the position of the tube relative to the center of resistance. The suggestion to place the headgear tube gingival rather than occlusal has been challenged by Worms et al. (1973). The effect in the former case is to raise the outer attachment points of the unaltered bow very slightly. Damon (1970) suggests positioning the headgear tube in the bicuspid region as it is closer to the center of resistance of the buccal segments. However, several authors (Worms et al., 1973; Bowden, 1978) note that the position of the tube should be established for convenience as plastic deformation to the outer bow is the best way to alter the location of the outer attachment points.

Several authors have noted that, upon loading, the inner bow may not act as a rigid body (Terlingen, 1973; Houghton, 1977; Jacobson, 
1979). Expansion or splaying of the arch gives rise to unknown buccal forces especially if the inner bow is not strengthened anteriorly. Houghton suggests that this effect can counteract the lingually directed force of an asymmetric unilateral headgear on one side. However, on the other side of the arch the buccal forces due to asymmmetric line of force and expansion of the arch will augment one another. Terlingen's claim that the asymmetric soldered facebow delivers unilateral forces must be based on the deformable behaviour of the inner arch. 


\subsection{Summary}

The Review of the Literature indicates that controversy and uncertainty still exists in headgear mechanics, especially when rotational effects are combined with translatory effects. Headgear forces have mainly been used for

(a) distalization and/or intrusion-extrusion,

(b) change in tip of the molars and/or differential distalization. Normal headgear therapy involves making a limited selection from the above four basic movements. However, movement along the lateral axis, and greater intrusion on one side than the other, may also be important orthodontic requirements.

The reported work on headgear up to this time has largely been based on two-dimensional analyses. The mechanical complexities of what is essentially a three-dimensional problem have received little attention. 
Statement of the Problem

Various styles of headgear have been advocated by certain clinicians, and the modifications they espoused are numerous. Each one of these prototypes was designed with a specific goal in mind but no underlying headgear philosophy has emerged. Headgear analysis to date has been limited to the two-dimensional case, either plan or elevation. Not withstanding this simplifying limitation no general solution to headgear mechanics has emerged. Thus, a unified theory of headgear mechanics, together with a logical and practical treatment method is presented.

Some of the difficulties that surround the analysis and application of headgear methods stem from a lack of clarity in the definition of the objectives of treatment. Consequently, it is assumed in the present work that the clinician must have a clear, quantitative statement of where the teeth are before treatment starts and a similar quantitative statement of where he wishes the teeth to be at the end of treatment. Similarly it is assumed that the clinician must clearly define the forces and moments which should be applied to achieve the required tooth movement. This is extremely important even if the headgear is used for anchorage purposes only. Such quantification enables the orthodontist not only to think about the force system far more clearly but also to monitor treatment and progress toward the final goals. Without such quantitative statements of treatment goals, forces and moments, a complex and difficult process becomes almost 
impossible to control.

From the literature it might well be assumed that the forces used to translate the buccal segments may also be used to produce any of the required moments. But a mechanical analysis of the problem shows that the above assumption is true in only a few cases and that, in general, forces cannot provide both the specified tooth translation and rotation simultaneously. Couples are essential if all three forces and moments are to be simultaneously available. Therefore, to fully understand headgear mechanics a general analysis is required.

The problem addressed in this work then, is to enunciate the relevant three dimensional force and moment compatibilities and to show how they may be used to generate a logical approach to headgear design. Such factors as the elastic deformation of the inner and outer bow when under load are considered secondary to the development of a general theory and, hence, are not considered. The goal has been to work towards a solution which will permit the clinician to place the emphasis on orthodontic treatment planning rather than on illdefined mechanical problems. To this end, an interactive computer assisted design program is presented, and an indication of the direction in which this aspect of the work might continue is included. 


\section{Materials and Method}

\subsection{Mechanical Principles}

The methods of analysis of headgear mechanics must clearly satisfy the basic principles of static equilibrum. Clarification of these principles is aided by defining space by three orthogonal axes (Fig. 3.1). These three axes are mutually perpendicular and intersect at the origin, "O", which for the present analysis is assumed to be coincident with the center of resistance of the buccal segments. The $\mathrm{x}-\mathrm{z}$ plane is oriented parallel to the occlusal plane. The axes also show sign, being positive in the direction indicated in Fig. 3.1 (a right handed system). Thus any point in space "p" may be defined relative to the origin by three orthogonal co-ordinates.

A force in general terms represents the action of one body on another and is described by

(1) its point of application

(2) its magnitude

(3) and its direction.

A force may be represented by a vector which is a mathematical expression possessing magnitude and direction. Throughout this thesis vector quantities will be distingushed by a superscript bar ie. $\bar{F}$. Because the point of application of a force must be uniquely described, the vector is fixed, and may not be repositioned without taking into account the effects of such repositioning. Any set of forces may be resolved into one equivalent force by vector addition. 


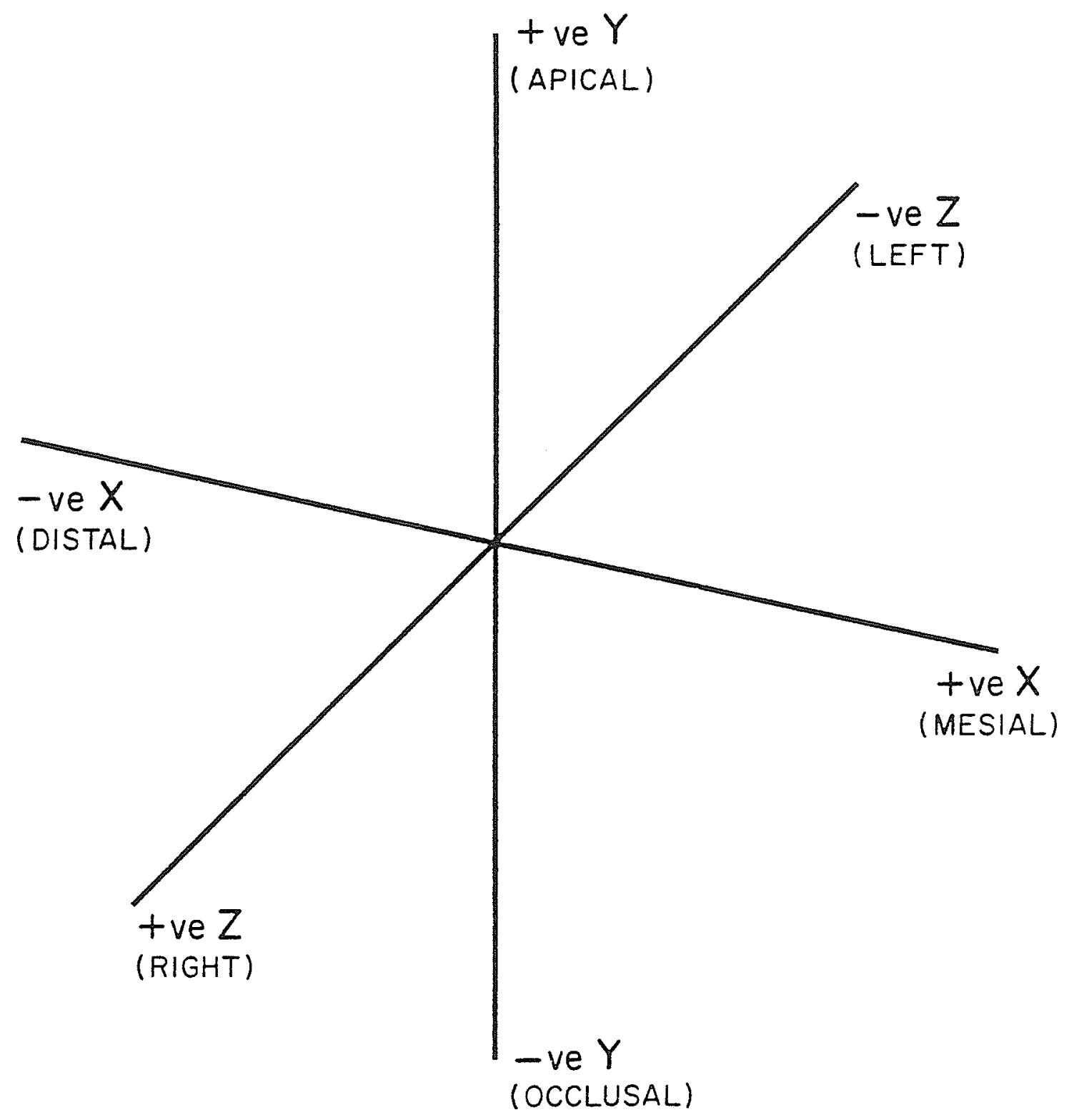

Fig. 3.1 Definition of axis systen. 
A force, $\bar{F}$, may also be represented by three mutually perpendicular components such that

$$
\bar{F}=F_{x} \bar{i}+F_{Y} \bar{j}+F_{z} \bar{k}
$$

where $F_{X}, F_{Y}$, and $F_{z}$ are scalar quantities and $\bar{i}, \bar{j}, \bar{k}$ are unit vectors.

The moment of a force, measures the tendency of the rigid body to rotate about some point. In vector terms the moment vector is defined as

$$
\overline{M_{0}}=\bar{r} \times \bar{F}
$$

where $\bar{r}=x \bar{i}+y \bar{j}+z \bar{k}$ and $x, y$ and $z$ are the coordinates of the point of application of the force, $\bar{F}$, relative to the origin, " 0 ". It must be noted that in Equation 3.2 the symbol X signifies a vector product which has special properties and does not represent normal multiplication. The moment $\bar{M}_{O}$ according to the definition of the vector product is perpendicular to the plane formed by $\bar{r}$ and $\bar{F}$.

It can be readily shown that the orthogonal components of the moment about the three mutually perpendicular axes are

$$
\begin{aligned}
& M_{X}=y F_{z}-z F_{Y} \\
& M_{Y}=z F_{X}-x F_{z} \\
& M_{z}=x F_{Y}-y F_{X}
\end{aligned}
$$

A special relationship is found when the sum of the forces is zero but the sum of the moments is non-zero. This is known as a couple and while translation will not occur there will be a propensity for rotation. The moment of a couple, $\bar{M}_{C}$, must be perpendicular to the plane 
containing the forces. Such moments are free vectors and may be assumed to act at any point on a rigid body.

The conditions for static equilibrum are satisfied when the resultant of all the forces and of all the moments are zero. Mathematically, these conditions are represented by

$$
\begin{aligned}
& \sum \bar{F}=0 \\
& \sum \bar{M}_{O}=0
\end{aligned}
$$

The three dimensional orthogonal representation allows the uncoupling of each axis relative to the plane formed by the other axes and permits the use of simple vector representation and algebra to solve given problems. However, vector manipulation may present a few unexpected complications to the uninitiated. Firstly, the vector product is non commutative, ie. $\bar{r} \times \bar{F}$ is not equal to $\bar{F} \times \bar{r}$. This is due to the unique right-hand triad formed by three vectors which is altered when the order is changed. Therefore the rules of normal algebraic multiplication do not apply. Secondly, the scalar product of two vectors is defined as $\bar{F} \cdot \bar{M}_{O}=F M_{0} \cos \theta$, where $\theta$ is the angle between the vectors $\bar{F}$ and $\bar{M}_{0}$, and $F$ and $M_{O}$ are their respective magnitudes. These two vector properties are extremely important in the understanding of the relationship of a force to the moment generated by that force. Any solution to headgear problems specific or general must adhere to the mechanical principles just enunciated. It will be shown that these principles aid the clinician by clarifying and illuminating the problem of headgear therapy.

In applying these principles four simplifying assumptions may be 
made:

(i) The forces required on the left and right segments may be represented by an equivalent force and moment system (rigid body assumption);

(ii) The center of resistance of the buccal segments is assumed to be where the mid-sagittal plane of the patient intersects a line drawn between the center of resistance of each side;

(iii) The two forces applied to the outer bow can always be made equivalent to $\bar{F}$ applied at $\bar{r}$

(iv) The inner and outer bows may be considered rigid.

The orthodontic significance of these assumptions is discussed in Chapter 5 .

In a solution of headgear mechanics, the orthodontist must specify the force and moment system required at the center of resistance of the buccal segments; then attempt to find the point of application of the force that will also give the required moments on the buccal segments. He is attempting to find $\bar{r}$ given $\bar{F}$ and $\bar{M}_{0}$. The noncommutative property of vector multiplication and the equation $\overline{\mathrm{M}}_{\mathrm{O}}=\bar{r} \quad \mathrm{X} \quad \overline{\mathrm{F}}$ dictates that this operation is not valid and that in general $\bar{r}$ cannot be found from a knowledge of $\bar{F}$ and $\bar{M}_{0}$.

As indicated, the required force on the buccal segments may be represented by a vector $\bar{F}$. If this force acts at a point "p" other than the center of resistance of the buccal segments a moment, $\bar{M}_{O}$, is produced about the origin (Fig. 3.2). A conventional and convenient way to represent such a situation is to transfer the force $\bar{F}$ from 


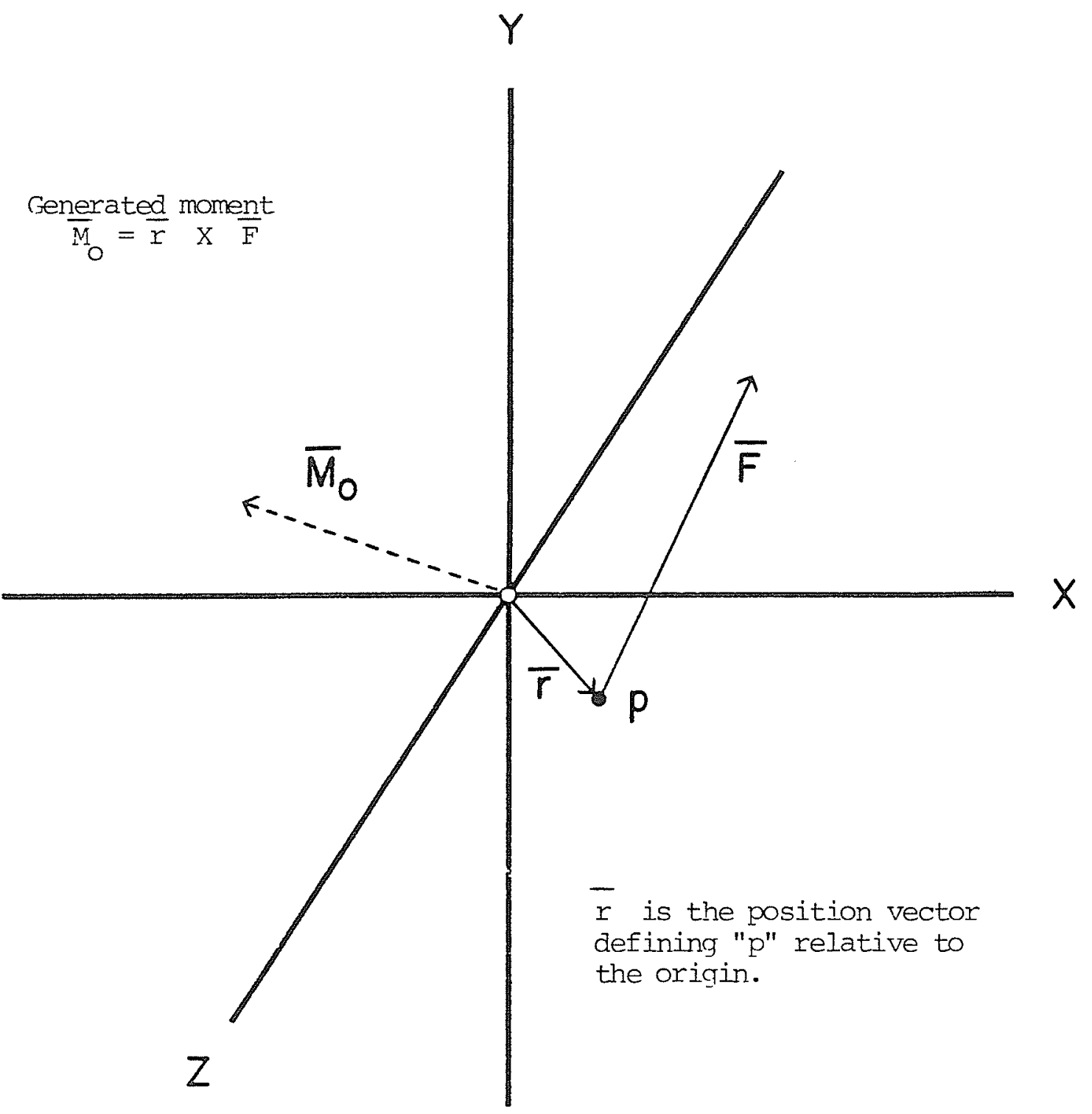

Fig. 3.2 Generation of a moment about the origin by a force " $\bar{F}$ " acting at point "p". 


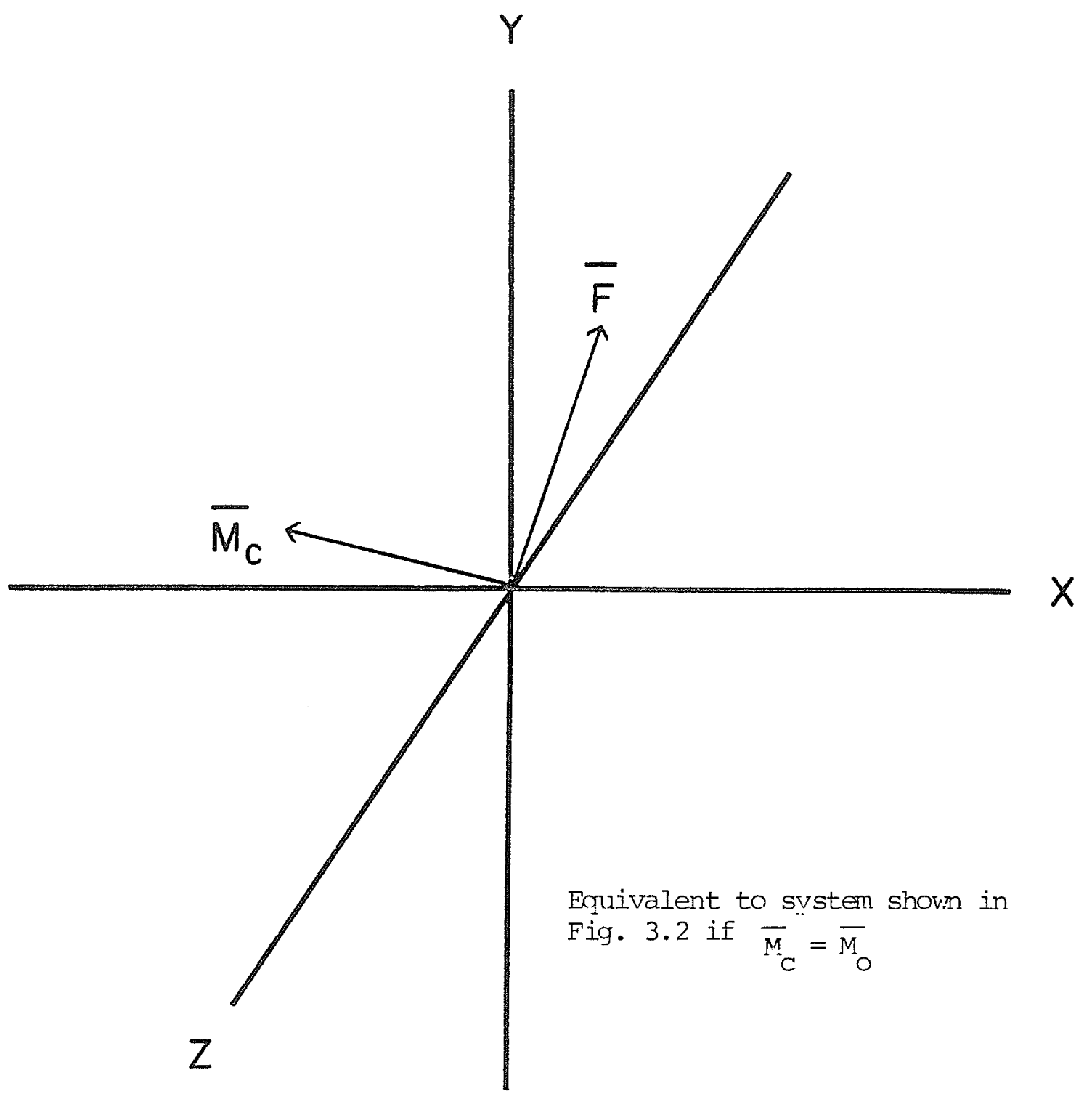

Fig. 3.3 Equivalent force-couple system. 
"p", to the origin and replace the rotational propensity by an exactly equivalent couple, ie. $\bar{M}_{O}=\bar{M}_{C}$. Because the net force of the couple is zero $\left(\sum \bar{F}_{C}=0\right)$ it may replace the rotational effect without altering the translation due to $\bar{F}$. This representation by a force acting at the origin and an equivalent couple, may be used for any force acting at a point in cartesian space (Fig. 3.3).

The couple vector may be represented by three orthogonal couples $M_{C X}, M_{C y}, M_{C Z}$ each made of a pair of forces equal in magnitude, opposite in sign, and with parallel lines of action. Thus, there are now implicitly nine forces; $F_{X}, F_{Y}, F_{Z}$, and the six forces of the three couples $\mathrm{M}_{\mathrm{CX}}, \mathrm{M}_{\mathrm{CY}}$ and $\mathrm{M}_{\mathrm{CZ}}$. Such a force-couple system in which $\bar{F}$ and $\bar{M}_{C}$ are non-zero, and in which they are not mutually perpendicular, cannot be reduced to an equivalent system made up of a single force acting at a position "p". This statement confirms in a physical way the mathematical conclusion reached earlier, namely, that $\bar{F}$ cannot in general produce $\overline{M_{0}}$.

The fact that the moment vector $\bar{M}_{0}$ must be perpendicular to the plane containing $\bar{r}$ and $\bar{F}$ may be conveniently summarized using the scalar product. In orthogonal terms this is expressed as

$$
F_{x} M_{x}+F_{y} M_{y}+F_{z} M_{z}=0 \text {. }
$$

Substituting Equations $3.3,3.4$, and 3.5 into Equation 3.7 gives

$$
F_{x}\left[y F_{z}-z F_{y}\right]+F_{y}\left[z F_{x}-x F_{z}\right]+F_{z}\left[x F_{y}-y F_{x}\right]=0 .
$$

This is a most important conclusion so far as headgear therapy is concerned. Firstly, Equation 3.7 shows clearly that an independent 
choice of $\bar{F}$ and $\bar{M}_{O}$ may not be made if $\bar{M}_{O}$ is to be generated by $\bar{F}$. Thus, for the perfectly general solution, $\bar{M}_{0}$ selected independently of $\bar{F}$, the rotational effects must be generated by couples. Such a separation of the moment generated from the translational force, removes the restriction dictated by Equation 3.7. Secondly, Equation 3.8 enables selection of compatible forces and moments to be made in cases where less than the full general solution is required. The simplest, example is that in which a force in the $\mathrm{x}$ direction and a moment about the $\mathrm{y}$ axis is required and all other components are zero. In this case, Equation 3.8 is not violated as can be seen by substitution,

$$
\mathrm{F}_{\mathrm{x}}[0]+0\left[\mathrm{zF}_{\mathrm{x}}\right]+0\left[0\left(\mathrm{~F}_{\mathrm{x}}\right)\right]=0
$$

and given $F_{X}$ and $M_{Y}$ a value of $z$ can be found to satify the moment requirement. Many intermediate cases between the full general case and this simple case can be dealt with by means of the fundamental methods just enunciated. Thirdly, Equation 3.8 is a reminder of the fact that all components of the force and position vectors must be defined in every case; eg. If no force along the $y$ axis is required then $F_{Y}$ must be set to zero in all of the relevant equations. Some of the confusion that seems to arise in considering headgear design likely stems from failure to obey this simple consequence of Equation 3.8 .

The foregoing principles of mechanics form a sound basis for making rational choices in headgear design even in cases where complex movements are required by the treatment plan. 


\subsection{Computer Application}

It is clear that practical use of the mechanical principles given in section 3.1 involve calculations and logical decisions. Such processes are ideally performed on a digital computer and to this end two programs have been written.

The first computer program was utilized to solve the mechanical compatibilities indicated by Equations 3.7 and 3.8 , with respect to the treatment plan of the orthodontist. The computer approach forces the programmer into a logical, systematic thought process, and a very precise understandng of the problem. The design of the program was such that a logical series of questions appear on the screen, and the response of the clinician dictates a particular pathway or loop. This allows the orthodontist to be in charge of making treatment decisions to suite his plans. The program is able to handle the three dimensional orthogonal components, rapidly calculate mathematical expressions and give a final or limited response. Depending on the information printed out by the computer the operator may then continue or return to an appropriate location in the program. This interactive approach allows the power of the mechanical principles to be consistently applied without interfering in any way with clinical judgement.

A second program which assists in the design of a limited range of headgear types has also been written. This takes the basic data derived in the first program together with relevant patient data and 
derives the appropriate forces and their attachment points to the face bow. The relevant geometric details are plotted for use as a template. This program is limited to the solution of cases involving a cervical strap but illustrates the general feasibility of this method of design. 
Results

\subsection{Vector Consequences:}

The mathematics involved in the general three-dimensional solution clearly shows that in most cases it is not possible to use the forces required for translation to also produce the rotations. Two approaches may be used. As indicated, couples are an accurate means of producing rotations while a force acting at the center of resistance can produce the required translation. Alternatively, Equation 3.7 illustrates that given the orthogonal forces, the moments produced by those forces may not be arbitrarily chosen. However, the generation of the required moments by the translatory forces may be clinically advantageous because it will generally lead to simpler headgear design. The problem of sorting out the mechanics, so that the required forces and moments are simultaneously compatible is solved by applying the logical consequences of the vector algebra.

To see how this objective may be achieved with quite complex headgear requirements reference may be made to the following example:

$$
\begin{array}{ccc}
F_{X}=-500 \mathrm{gm} . & F_{Y}=-200 \mathrm{gm} . & F_{z}=0 \mathrm{gm} \cdot \\
M_{X}=0 \mathrm{gm} \cdot \mathrm{mm} . & M_{Y}=3000 \mathrm{gm} \cdot \mathrm{mm} . & M_{Z}=-3500 \mathrm{gm} \cdot \mathrm{mm} .
\end{array}
$$

Substituting these numberical values into Equation 3.7 gives

$$
0+(-200)(3000)+0=600,000 \mathrm{gm} . \mathrm{mm} .
$$

which clearly does not satisfy the required equality to zero. Consequently, the moments cannot be generated by the simultaneous application of the translatory forces $F_{X}$ and $F_{Y}$ in this case. 
Further inspection of the problem shows that if it is partitioned into two problems then the moments may be separately generated by $F_{X}$ and $F_{Y}$ in sequence. Such partitioning at $F_{y}-M_{y}$ yields,

$$
\begin{array}{lll}
F_{X}=-500 \mathrm{gm} . & F_{Y}=0 \mathrm{gm} \cdot & F_{z}=0 \mathrm{gm} . \\
M_{X}=0 \mathrm{gm} \cdot \mathrm{mm} . & M_{Y}=3000 \mathrm{gm} \cdot \mathrm{mm} . & M_{z}=0 \mathrm{gm} \cdot \mathrm{mm} .
\end{array}
$$

$$
\begin{array}{lll}
\text { (ii) } F_{X}=0 \mathrm{gm} . & F_{Y}=-200 \mathrm{gm} . & F_{z}=0 \mathrm{gm} \cdot \\
M_{X}=0 \mathrm{gm} \cdot \mathrm{mm} . & M_{Y}=0 \mathrm{gm} \cdot \mathrm{mm} . & M_{z}=-3500 \mathrm{gm} \cdot \mathrm{mm} .
\end{array}
$$

It is now clear that partitioning allows a sequencing of treatment such that equality of equation 3.7 is satisfied in both phases. In clinical terms this example shows that differential distalization, extrusion, and change in the cant of the buccal segments cannot be simultaneously achieved by translational forces without giving rise to an unwanted side effect. Inserting the required variables into Equations $3.3,3.4$ and 3.5 we find

$$
\begin{gathered}
M_{X}=0=-z(-200) \\
M_{Y}=3000=z(-500) \\
M_{z}=-3500=x(-200)-y(-500)
\end{gathered}
$$

From these it is clear that no value of $z$ may be found to satisfy both equations 4.1 and 4.2 , if $F_{X}$ and $F_{Y}$ are simultaneously applied. If the treatment goals are to be satisfied, ie. $z=-6 \mathrm{~mm}$, an unwanted $M_{X}$ will be generated. Partitioning at $F_{Y}-M_{Y}$ means that $F_{X}$ is used to generate $M_{Y}$ and then in a separate treatment phase $F_{Y}$ is used to generate $M_{Z}$, and the inequality between 4.1 and 4.2 is avoided as is the 
unwanted ${ }^{M} \mathrm{X}$

Discussion of orthodontic implication of partitioning is deferred to Chapter 5 but it is recognized that partitioning of the solution implies the temporal sequencing of treatment. 


\subsection{Computer Partitioning:}

The computational processes needed for the partitioning example given in the previous section are best performed on a small digital computer. Not only does this ensure that calculations are correctly performed but it also ensures that the input and output of the data is organized in a logical and permanent manner.

In the program the equations given in Chapter 3 are used to determine the need for partitioning, the relevant values of $\bar{r}$, and to indicate which forces, or couples are to be used to produce the required rotations. To determine $\bar{r}$ Equations $3.3,3.4$ and 3.5 are involved and it should be noted that each of these equations contains two components of $\bar{r}$. In general, then, no unique values for the components of $\bar{r}$ can be obtained from these equations. To overcome this difficulty it is necessary to make some arbitrary choices. The choices made in the program are to set the appropriate element of $\bar{r}$ in each equation to zero.

The way the results are tabulated may be seen by referring to Example 4.1. The top matrix is a record of the force and moment system required by the treatment plan. The $x, y$, and $z$ components are given from left to right, respectively. Below this, is a matrix which indicates the computed co-ordinates of $\bar{r}$. If the mechanical requirements are not simultaneously compatible the appropriate partitioning is indicated. Under the heading "Proposed Mechanics" the logical consequences of the partitioning processes are given in terms of the most 
appropriate way to generate the required moment. If no moment is called for, of course, no force or couple is required and "NA" (not applicable) is shown.

To show the value of the computer program, six examples have been selected from the wide range of hypothetical treatment plans that were tested. Such selection is made necessary by the fact that the requirement of treatment plans may be as simple as one force or as complex as three forces and three moments. Selection was based on the desire to indicate the clinical consequences of the mechanical analysis presented in this thesis. These examples are discussed later but it is useful at this point to compare Example 4.4 with that given at the beginning of this chapter. The proposed force and moment system is the same in both examples and therefore their comparison will assist in understanding the computer print out in orthodontic terms. 


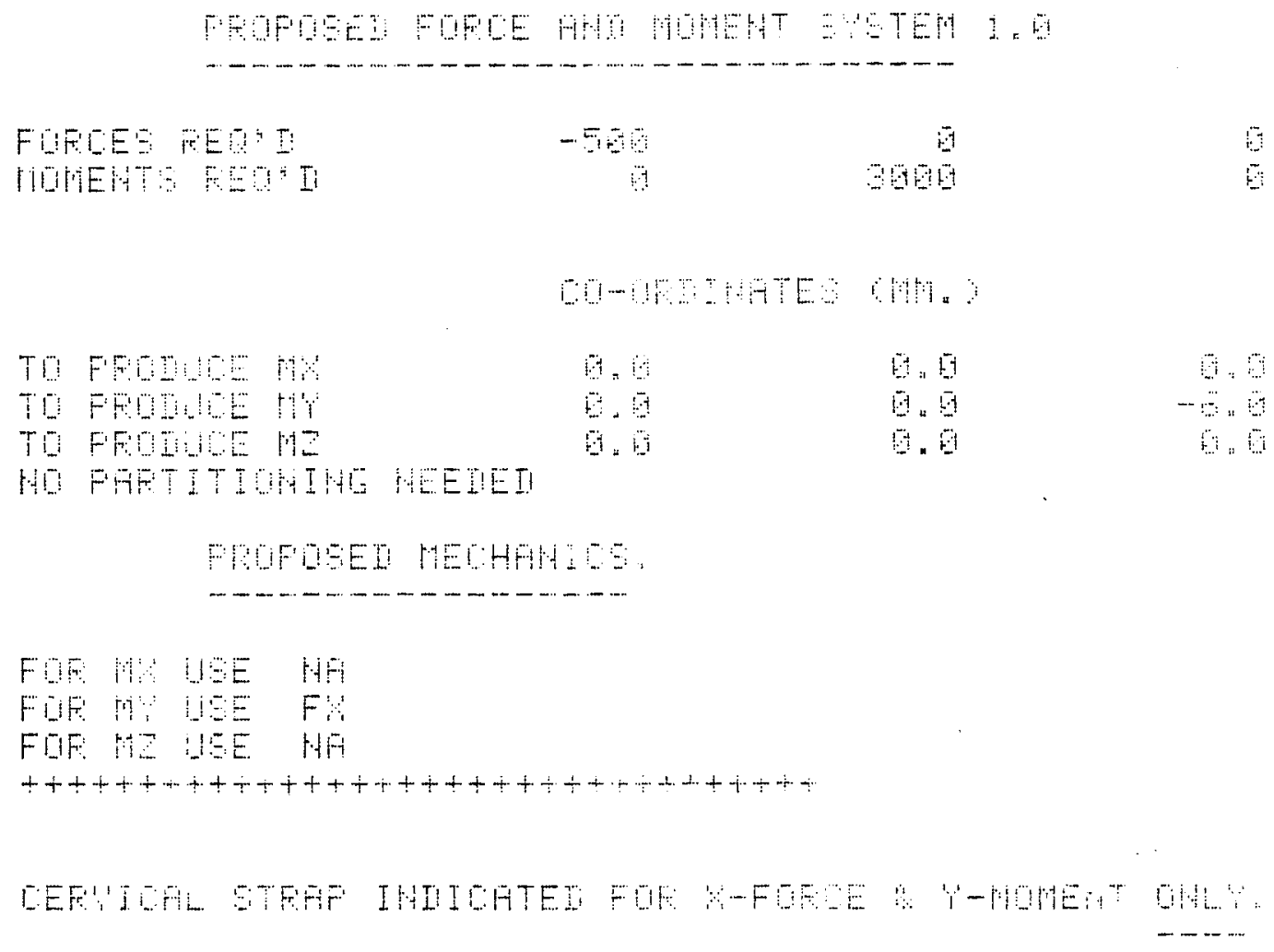

Note: Columns of figures represent $x, y, z$ components left to right respectively.

Example 4.1 Force/moment system required for differential distalization. 


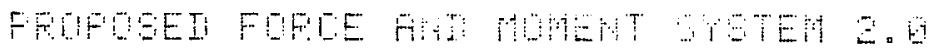

-

FOFEE TEE'I

MUITEUTS FEU!"

$-5+10$

$-29$

1.1

250

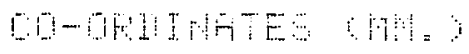

TO FrOWUE Min

1.9.

6.6

is

1.

5.

5.6

12.

TOFPIIIE HE

FHFTIIU FT FH-H

FEOFOEET METHADE.

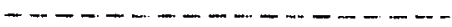

FOF HE UE $F$

FUF HU UEE HH

FQIF: HE HA

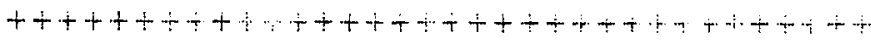

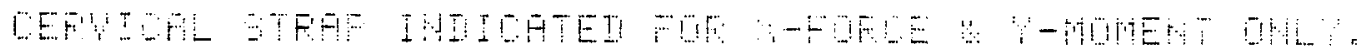

Note: For column headings see Example 4.1.

Example 4.2 Force/moment system recuired for distalization and differential extrusion. Partitioning at $\mathrm{F}_{\mathrm{x}}-\mathrm{M}_{\mathrm{x}}$ 


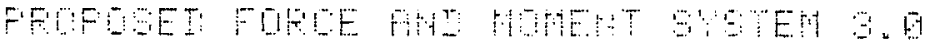

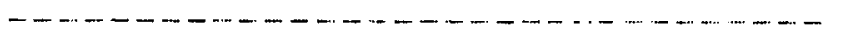

FITEE REO I

MIETTS FEOS

$\begin{array}{rl}9 & -200 \\ 2501 & 300\end{array}$

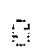

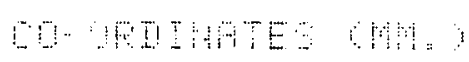

TO FHOUE TIS

9.:

a.

1.

0.7

a.

THFOE HE

1.9.

125

a

B.

FFFTITIOH HT

$F^{\prime}-1+1$

FFUPGEDI PEHFHIC.

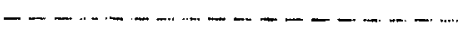

FOF WO HEE FU

FUF HO UEE OUIPLE

Flir He

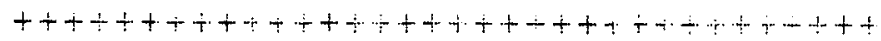

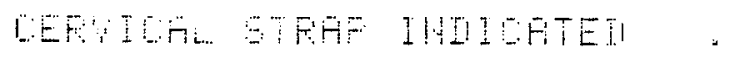

Note: For colum headings see Example 4.1.

Example 4.3 Force/moment system requiring one force but two moments. $M_{y}$ must be produced by a couple. 


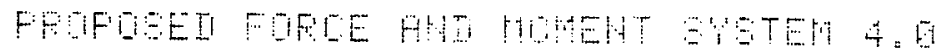

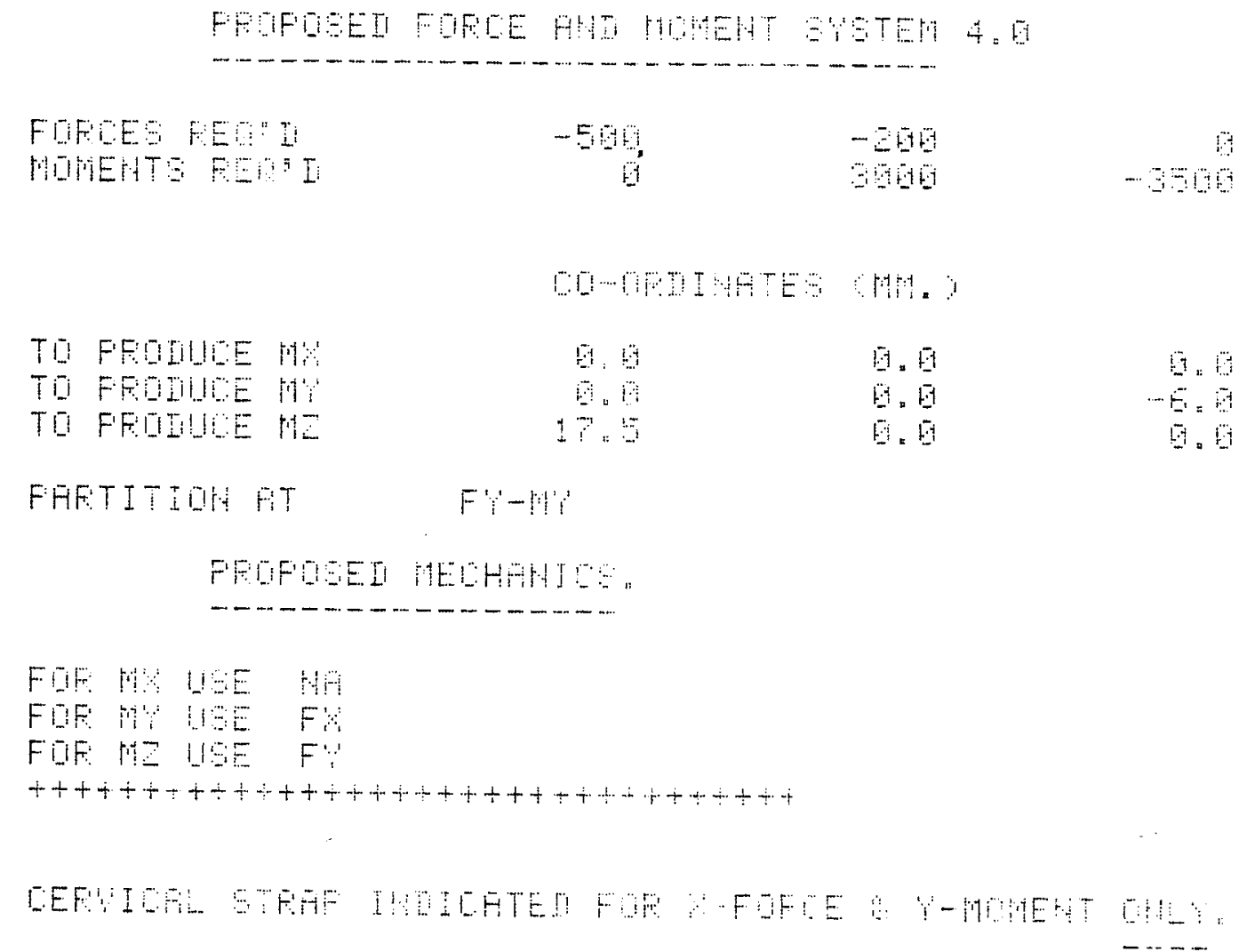

Note: For colum headings see Exarmle 4.1.

Example 4.4 Fequired force/moment svstem used in Section 4.1. 


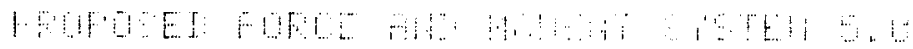

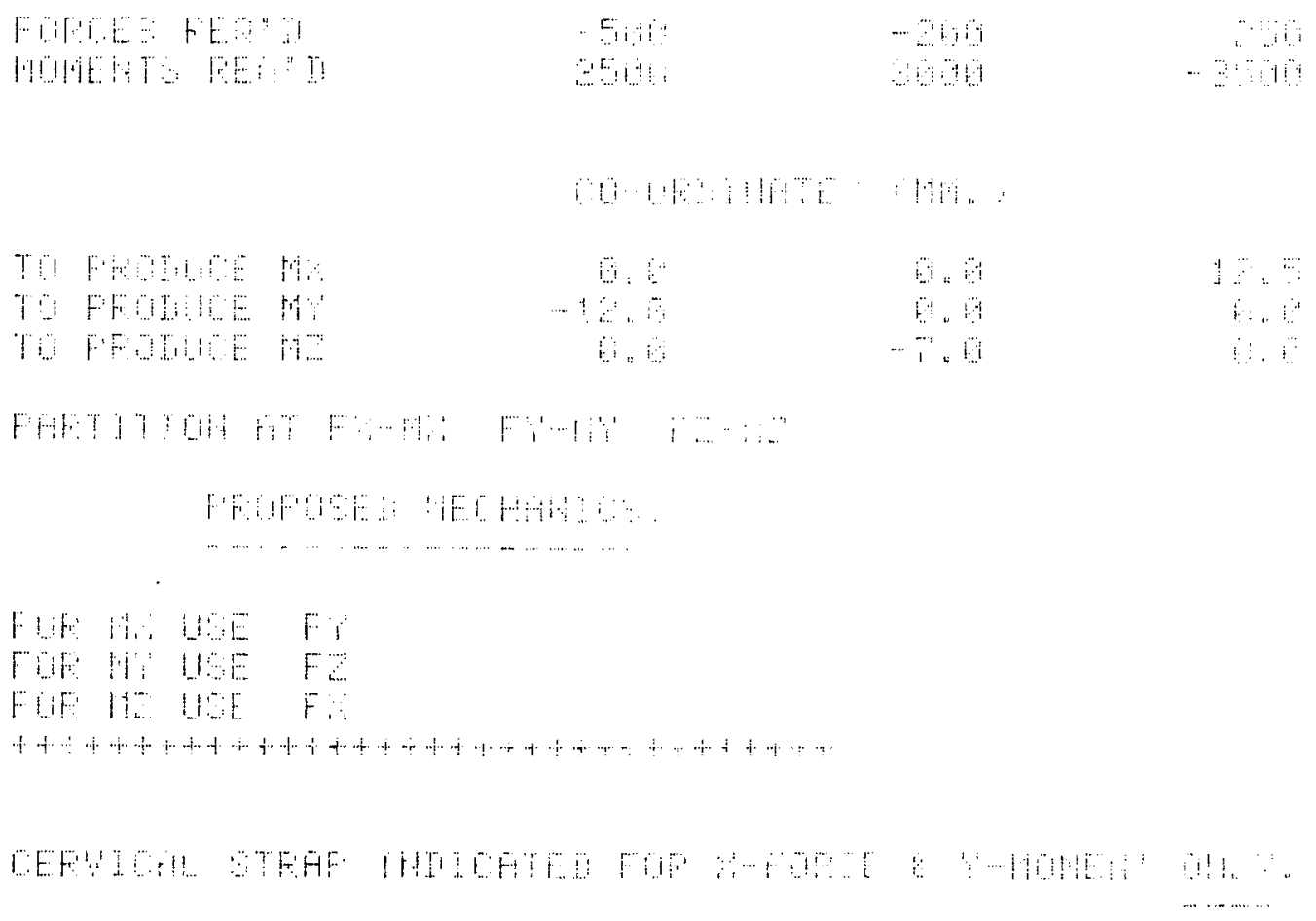

Note: For column headings see Example 4.1.

Example 4.5 The most complex force/moment system renuiring three forces and three moments. 


\begin{tabular}{|c|c|c|c|}
\hline \multirow[t]{2}{*}{$\begin{array}{l}\text { FFCES REO J } \\
\text { MUHEHT }\end{array}$} & $\begin{array}{r}549 \\
20106\end{array}$ & $\begin{array}{l}-600 \\
-600\end{array}$ & $\begin{array}{r}4 \\
-200\end{array}$ \\
\hline & OB-in & and. & \\
\hline 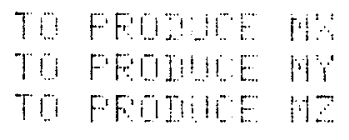 & 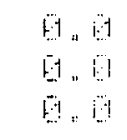 & $\begin{array}{r}0.9 \\
-6 \cdot 6\end{array}$ & $\begin{array}{lll} & \cdots \\
\cdots & \cdots\end{array}$ \\
\hline
\end{tabular}

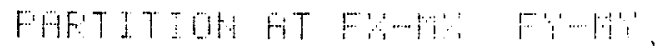

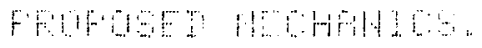

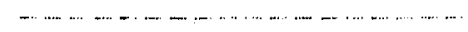

Fue M USe Fi

F F H HE

FUF: HE USE FE

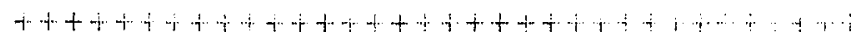

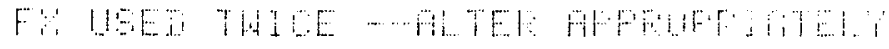

Note: For column headings see Example 4.1.

Example 4.6 Recuired force/moment system has two forces but three momonts. $F_{x}$ used to generate both $M_{y}$ and $M_{z}$. 
4.3 Computer Aided Design:

To indicate the further use of the data computed in the mechanics program an example of the output from the headgear design program is given in Figures $4.1,4.2$ and 4.3.

Since the output from the mechanics program is used in the design program it is appended to the patient data as shown in Figure 4.1 . The patient data required for the correct application of extraoral force is:

1. Arch lenth ( $A L$ ) and buccal width (BW). Arch length is defined as the distance from the maxillary incisal edge to a line drawn between the mesial surface of the maxillary first permanent molars. Buccal width is the distance between the mesial buccal cusps of the maxillary first permanent molars.

2. Gonial width (GW) and the $\mathrm{x}, \mathrm{y}$ co-ordinates of gonion relative to the $z$ axis. The position of gonion for purposes of this thesis is located at the greatest lateral width of the mandible near the angle of the jaw.

3. Cervical width. This is a soft tissue measurement of the lateral width of the neck at the level of the third cervical vertebra. 4. Cranial dimension. This measurement is the greatest antero-posterior measurement of the cranium.

5. Distance and angle of cervical point. These measurements are the distances from the cervical anchor point to the center of resistance, and the angle between the occlusal plane and the line joining the eer- 
vical anchor point and the center of resistance.

In the practical application of these definitions, the distances were measured in millimeters and the angle in degrees.

Using the mechanical requirements for a unilateral headgear (Example 4.1), and the patient data, a plot showing a plan view of the arch, the back of the neck, and the required lines of action of the two outer bow forces is generated. Figure 4.2 illustrates the need for a buttressed neck strap and this accounts for the gap between the line of action of the force and the outline of the neck on the left hand side. Discussion of the idea of the buttressed neck strap follows in Chapter 5.

In Figure 4.3, a side view is plotted to show the relationship between the occlusal plane and the line of action of the forces. The plot is oriented so that the occlusal plane is parallel to the $\mathrm{x}$ axis. The outline of the cranium and the back of the neck is a mathematically derived curve, approximating the mean outline of six posteroanterior cephalograms taken from clinical records. A test is made in the program to determine if a cervical strap is indicated. For a positive outcome of this test the line of action of the force must point to the third vertebra to within an accuracy of plus or minus ten degrees. Under normal conditions this will ensure that the required force and moment system will be achieved.

The computer plots that are the main output of the design program are normally to full-scale so that a direct template is formed. 


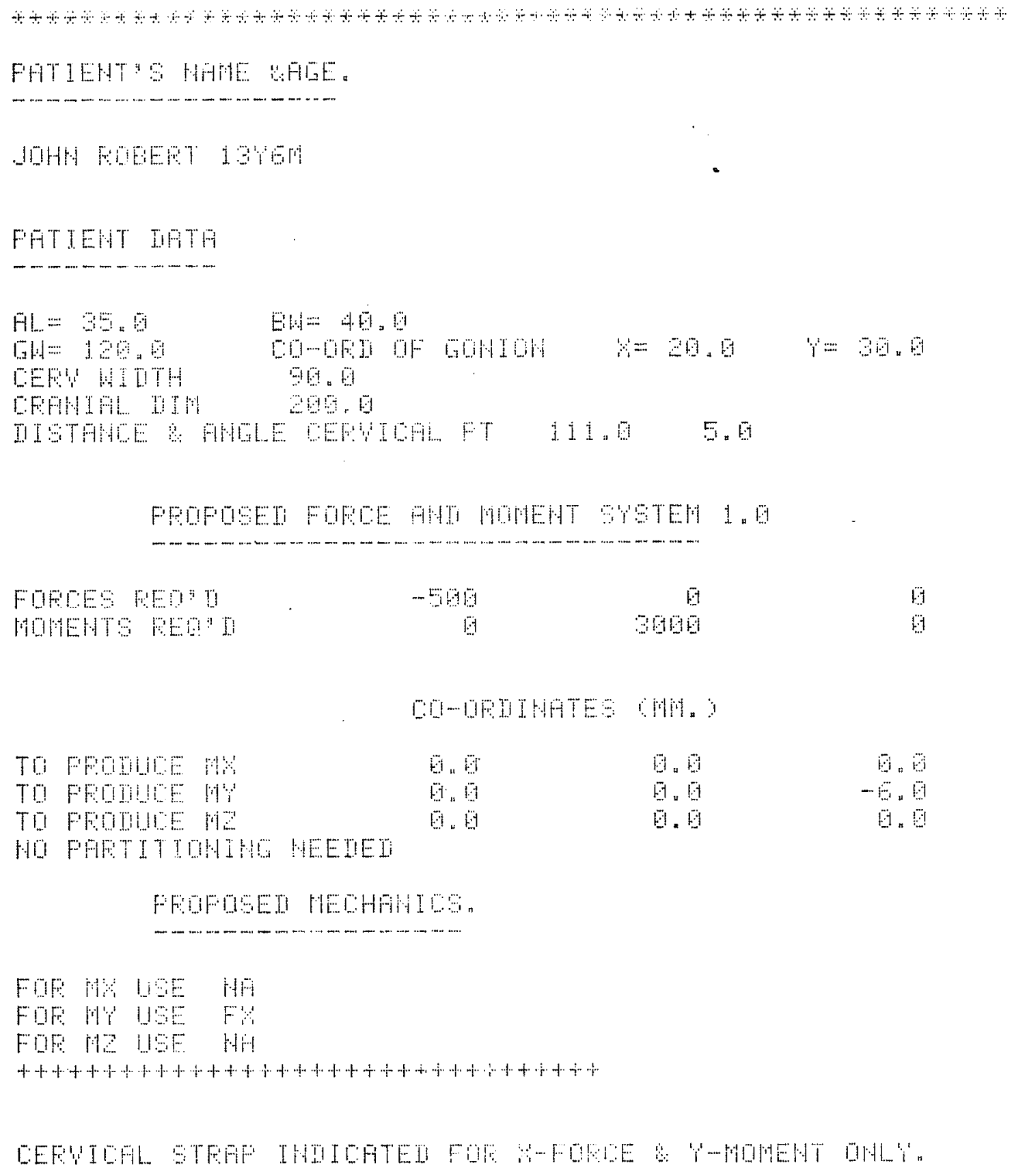

5. 0

6.

i.

TH Pritile

HO FHOTT TOHIHG HEEMEI

FFOFUED HETHAHISE

FOF Ha UE

For H W

For 12 ise

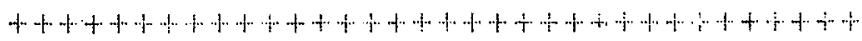

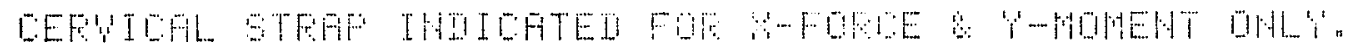

Fig. 4.1 Proposed force system appended to pertinent patient data. 


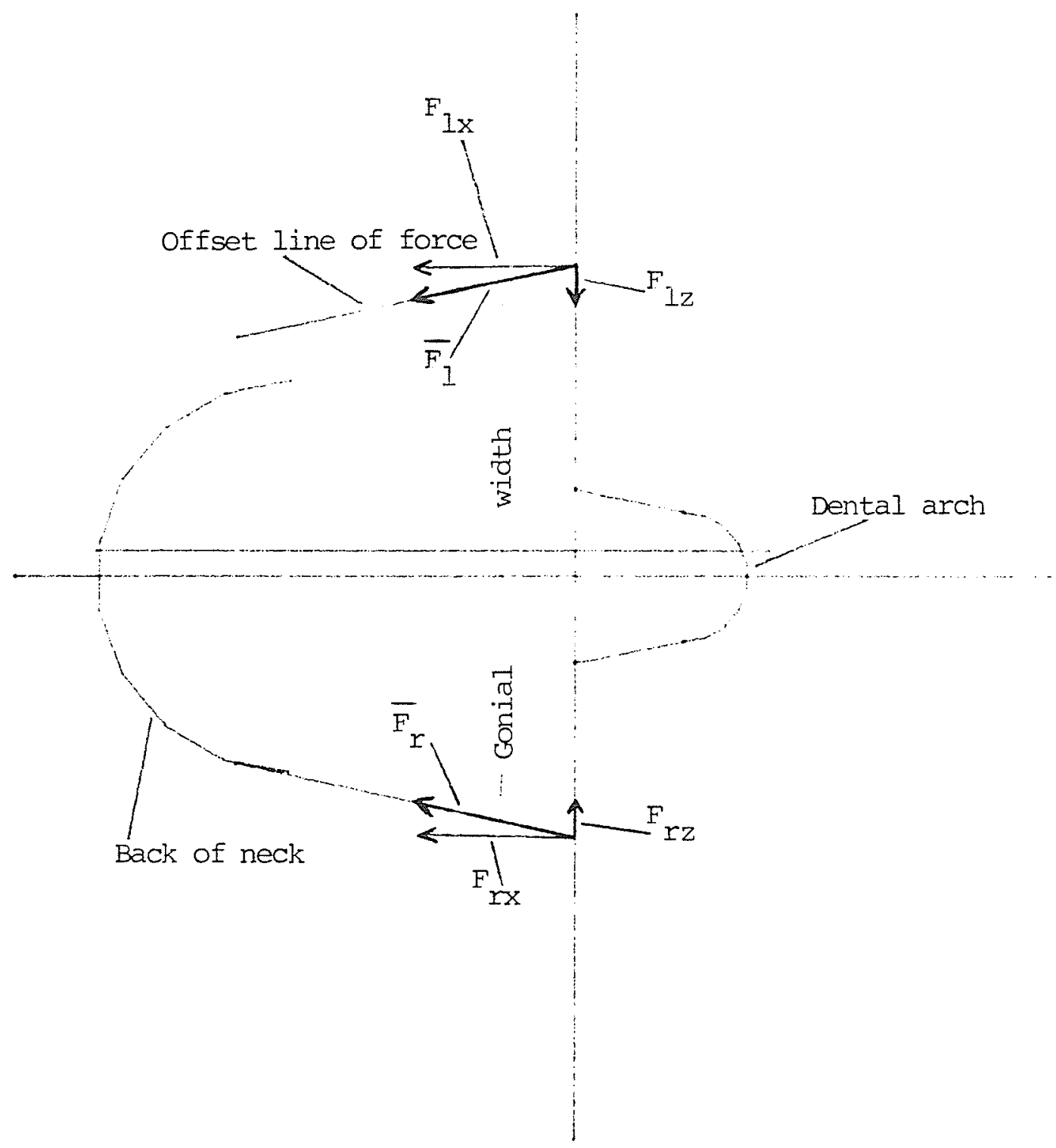

Fig. 4.2 Plan view of buttressed neck strap. 


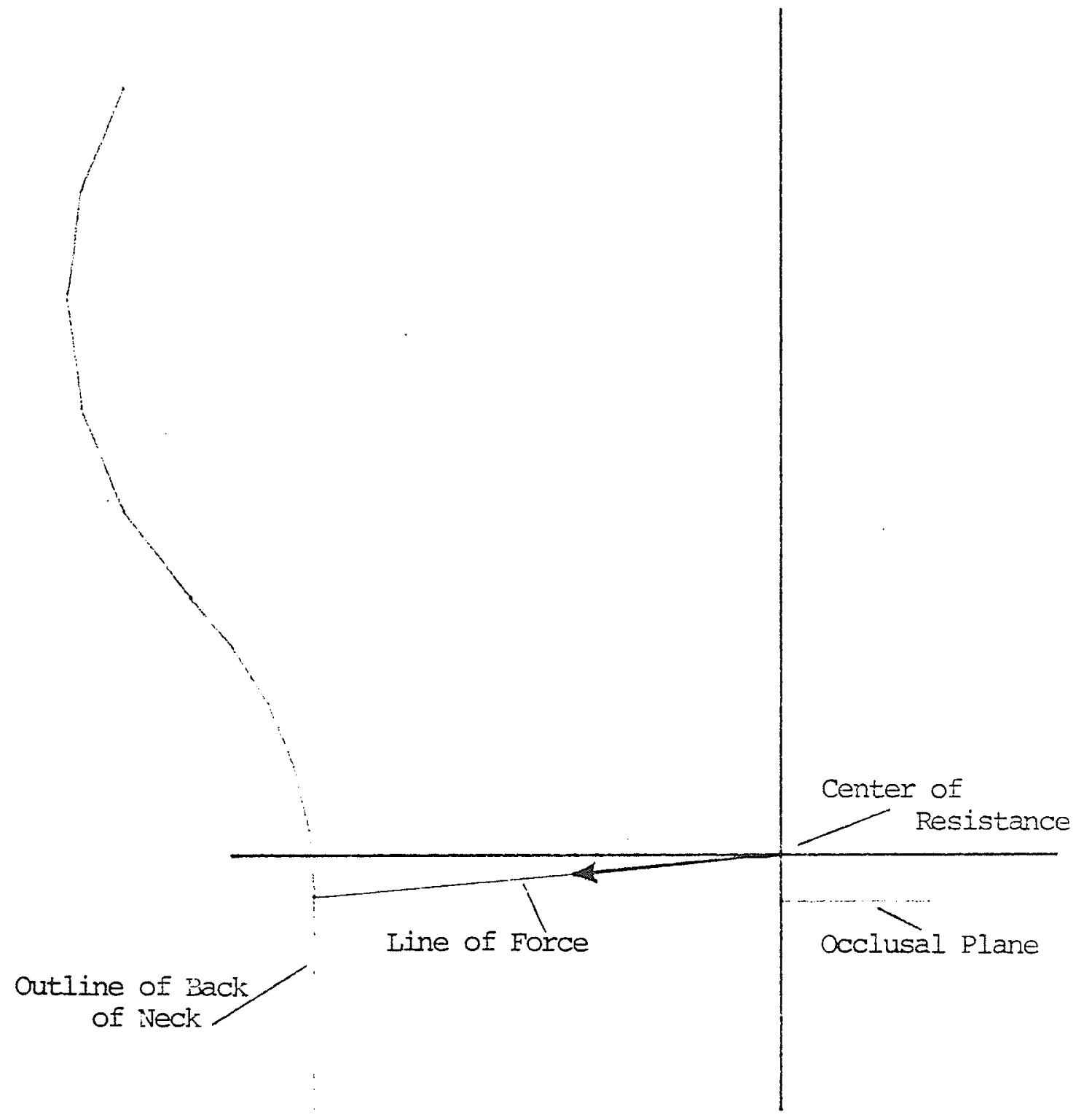

Fig. 4.3 Elevation showing Iine of force with cervical ilecji strap. 


\section{Discussion of Results}

\subsection{Introduction:}

A fundamental rethinking of the headgear problem has been initiated in this work. Rather than analysis, or modification, of existing extra-oral anchorage systems, a new approach using treatment requirements and mechanical compatibilities is used. The orthodontist must decide on the three forces (Fx, Fy, Fz) and the three moments ( $M x$, My, $\mathrm{Mz}$ ) required on the maxilla, even if the desired magnitudes are zero. In other words, the inescapable consequence of the algebra is that in clinical treatment all cases must be viewed as three dimensional problems and even the first level of treatment planning must proceed on this basis. This is one of the fundamental differences between the philosophy presented here and the conventional view of headgear design and analysis. 


\subsection{Sequencing:}

Partitioning has already been introduced (Section 4.1) as a method of avoiding undesirable side effects. In the example given in Section 4.1 it is clear that two separate phases of treatment are required if the forces of translation are also to generate the desired moments. In addition, it is shown that failure to sequence the treatment into the two phases results in an unwanted and significant differential extrusion of the buccal segments. Similar, unwanted effects may be detected in all of the examples where partitioning is called for. Although this is shown in a limited number of cases in this thesis, this result is general.

Sequencing of two or three phases of headgear therapy must involve orthodontic judgement. Considering the example just quoted a decision as to treatment priorities must be made. Such factors as space limitation, likely level of patient cooperation, and deep-bite or Class II tendency will be important in this decision process. Here, only the orthodontist can decide if differential distalization should take priority over extrusion and change in the cant of the buccal segments. Similar sequencing decisions are required in many cases. For instance, Example 4.2 illustrates that differential extrusion is not compatible with distalization. If sequencing is not used in this case a large unwanted side effect is introduced. Substituting the numerical values in Equation 3.4 yields; 


$$
\begin{aligned}
M_{Y} & =(12.5)(-500)-0 \\
& =-6250 \mathrm{gm} . \mathrm{mm} .
\end{aligned}
$$

This will clearly cause rotation about the vertical, or $y$, axis ie. differential distalization, if simulataneous application of forces is attempted. The dictates of a particular case may cause the clinician to perform the differential extrusion first leaving the distalization to a second phase of treatment. In another case the reverse order may be selected. Orthodontic judgement is the only way of deciding the particular sequencing. 


\subsection{Force Sharing:}

The discussion in Section 5.2 involves the idea of simple partitioning and sequencing. An additional dimension to sequencing is that of allowing one force to sequentially generate two moments. Clarification of this idea proceeds most easily with the aid of Example 4.6, in which only two forces are available to generate three moments. The proposed mechanics uses $F_{X}$ to generate both $M_{Y}$ and $M_{Z}$, but calculates the component of $\bar{r}$ on the assumption that the full value of $F_{X}$ is available for both moments. What is not taken directly into account in the program is the temporal nature of force application in orthodontic treatment. Therefore, if the distalizing force is to be used to generate the two moments sequentially the components of $\bar{r}, y$ and $z$, must be increased. Alternatively, $F_{X}$ may be reduced in magnitude for one or both phases of moment generation provided that appropriate changes in $\bar{r}$ are used to give the required moment to force ratio. Here again, judgement is called for, and attention is drawn to this requirement in the computer print-out.

Example 4.5 illustrates the most complex type of force and moment system (ie. three forces and three moments). The proposed mechanics calls for three treatment stages, whereby each force sequentially produces a required moment. Other solutions such as force sharing are possible, but again, this is a matter of orthodontic decision. 


\subsection{Couples Generated By Force Pairs:}

Though the sequencing and other techniques mentioned help in solving many complex headgear problems there are situations in which they do not offer a solution. Such a situation is found in Example 4.3 in which one force and two moments are called for. The proposed mechanics indicate $\mathrm{M}_{X}$ generated by $\mathrm{F}_{Y}$, and $\mathrm{M}_{\mathrm{Y}}$ generated by a couple. This latter is a consequence of there being no force perpendicular to the $\mathrm{y}$ axis. There is no incompatibility in this force-moment system because a couple is a free vector. Partitioning is indicated, however, to signal the fact that separate force systems are necessary.

The idea of a couple and how it may be produced in clinical practice needs some explantion. From the basic definition given in section 3.2 each of the orthogonal couples must be produced by two forces equal in magnitude but opposite in sign, and perpendicular to the required axis of rotation. The propensity for rotation is then calculated as the magnitude of the force generating the couples times the perpendicular distance between the two forces. If the couple is to be maintained, theory indicates that the forces generating it must remain constant. In practice this means that the anchor unit must maintain its position with respect to the dentition under all circumstances. Orthodontically, this may be possible if an inextensible headstrap is used on the oblate cranial form. By this means the anchorage forces are transfered to normal forces at the headstrap/cranium interface. Hence, a sensibly rigid constraint rather than a frictional constraint 
is provided.

A proposal for a headgear that can deliver both couples and translatory forces is shown in Figure 5.1. A circular metal frame lateral to the center of resistance could support the forces required for a moment. Springs connected from the outer bow to the circular frame would then produce the couples. As an example a moment about the vertical axis could be achieved by attaching the spring on one side in an anterior direction but on the opposite side in a posterior direction (Figure 5.2). Forces of $23 \mathrm{gm}$. separated by $130 \mathrm{~mm}$. and forming a couple produce a moment of $3000 \mathrm{gm} . \mathrm{mm}$. (similar to the moment requirement of Example 4.1). Thus, it may be seen that clinically useful moments can be produced by light forces. Because the forces producing the couple are equal but opposite, rotation is the only mechanical result and no side effects are produced. A couple may be used to produce the required moment in all cases, obviating the need for sequencing. However, complete headgear must then be used whenever a moment is required. 


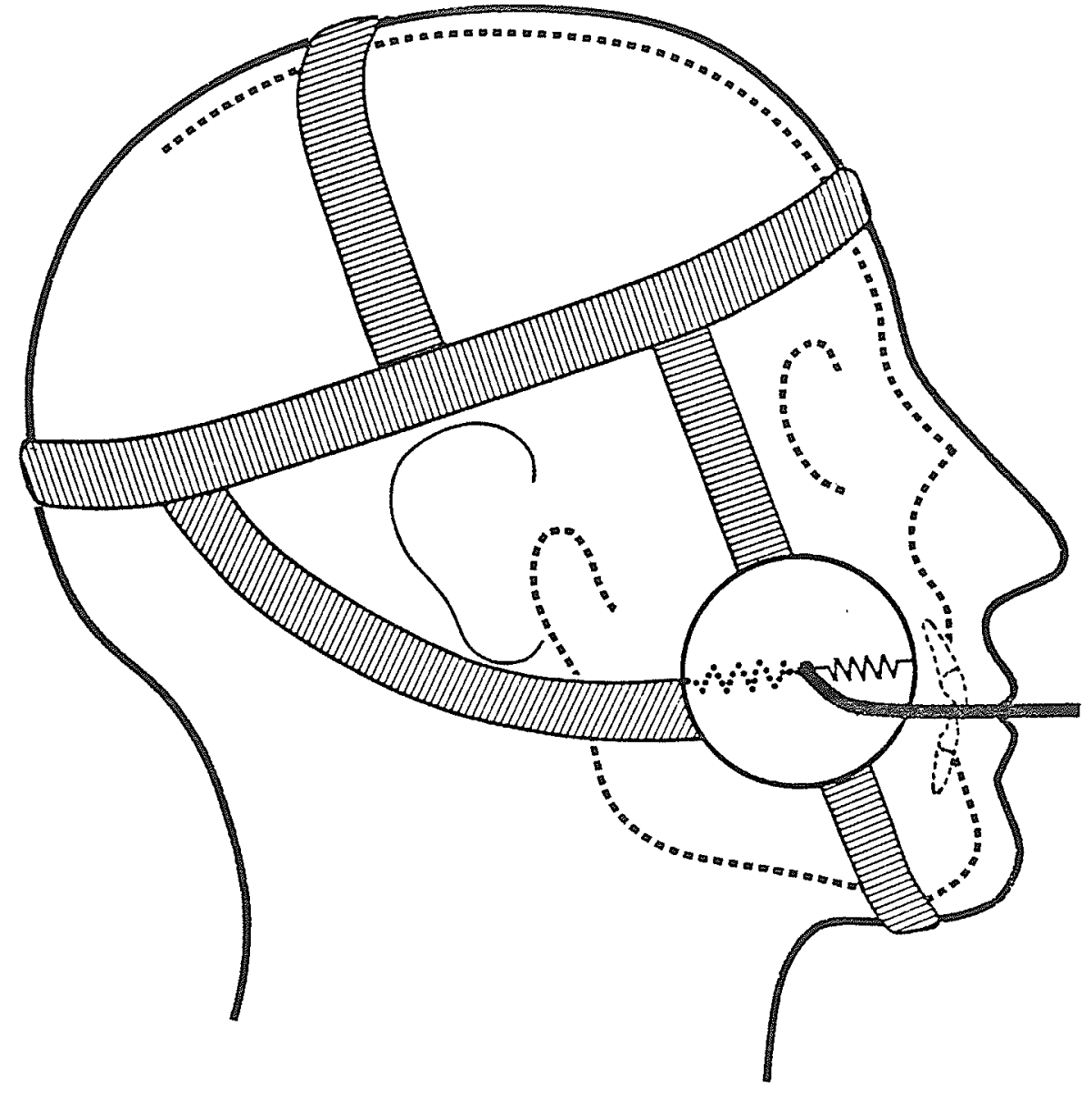

Fig. 5.1 A proposed headgear to generate the recuired moment by means of a couple. 


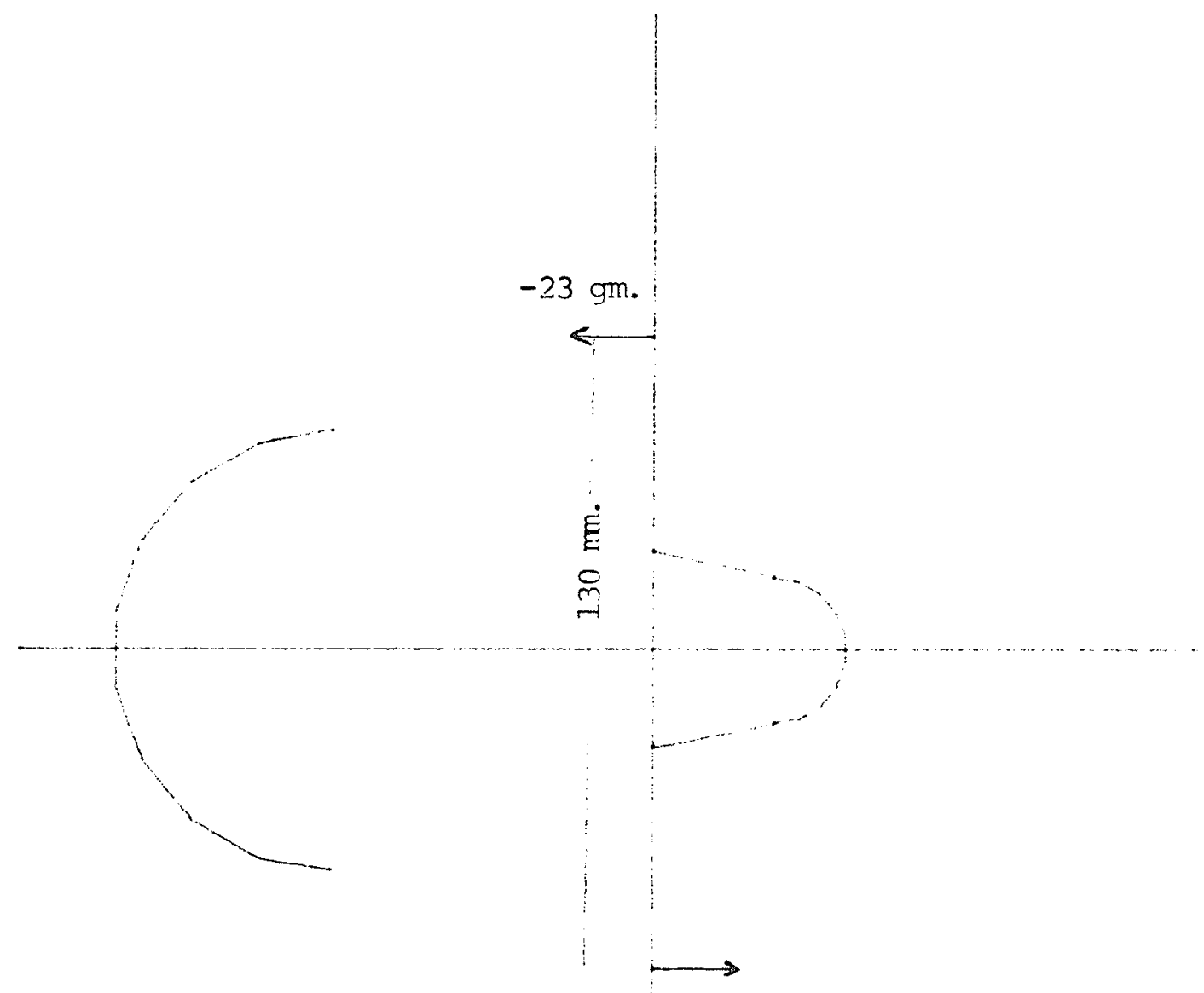

$23 \mathrm{gm}$.

Fig. 5.2 Plan view of mechanics using a couple for monent ceneration. 
5.5 Replacement of $\overline{\mathrm{F}}$ By Two Forces:

The application of the theory presented in Section 3.1 depends upon assumption (iii), namely, equivalence between a pair of headgear forces and a single force applied at the tip of $\bar{r}$. To ensure this equivalence in all cases the following restrictions are proposed:

(i) That the points of application of the two forces $\bar{F}_{I}$, $\bar{F}_{Y}$ to the outer bow be on a line parallel to the $z$ axis. This line must also pass through the tip of $\bar{r}$,

(ii) that the left and right attachment points be equidistant from the tip of $\bar{r}$,

(iii) that the sum of the left and right forces, be equal to the required force $\bar{F}$ ie. $\bar{F}=\bar{F}_{1}+\bar{F}_{Y}$.

Together, restrictions (i) and (ii) simply assure that no spurious moment is generated by $\bar{F}$ at the tip of $\bar{r}$. Restriction (iii) simply states that the applied force system must be that required for treatment.

It is readily admitted that, though sufficient, these restrictions are not exclusive. Other practical restrictions for satisfying equivalance may be proposed but those given are considered the simplest for use in headgear design. 


\subsection{Buttressed Neck Strap:}

The foregoing restrictions lead naturally to the consideration of a method of producing differential distal forces without introducing an unwanted lateral force, $F_{z}$. Figure 4.2 shows that the $x$ and $z$ componets of the applied forces will sum to the required force in this plane. This follows from the fact that the magnitude of the left and right forces are identical and, therefore, that $\mathrm{F}_{I z}+\mathrm{F}_{I Z}=0$ and $F_{1 x}+F_{r X}=F_{x}$. The moment, $\bar{M}_{0}$, is generated by $\bar{F}$ acting at a distance along the $z$ axis from the center of resistance.

To satisfy restrictions (i) and (ii), quoted in the previous section, the left attachment point must be appropriately further from the center of resistance than the right attachment point. Satisfaction of restriction (iii), then, clearly dictates that the line of action of the left force will not be tangential to the outline of the neck. A practical method of accomplishing this goal is to augment the neck strap on one side. The amount of augmentation, or buttressing, necessary is dependent upon the $z$ component of $\bar{r}$. If no spurious moment is to be generated, $\quad \bar{F}_{I}$ and $\bar{F}_{r}$ must be equidistant from the tip of $\bar{r}$ and this defines the required buttressing. The template for fabrication of an outer bow with appropriate attachment points, and the neck strap buttressed on one side utilizes the full scale design program and is illustrated in Figure 4.2. Although only one example is shown buttressing is offered as a precise and practicable method of providing assymetric force systems for differential distalization. 


\begin{abstract}
Figure 4.3 shows the side elevation of the same case. This indicates the line of force defined by the orthodontic requirements, and the patient anatomy. If the cervical neck strap is used the anchor point at the back of the neck must be close to the third cervical vertebra. If no moment is required about the $\mathrm{z}$ axis, the line of force must also pass through the center of resistance. The computer is programmed to test if the resultant line of force coincides with the line of force possible with a cervical neck strap. If these lines of force are within 10 degrees of one another the cervical neck strap is indicated. If a moment about the $z$ axis is required, and if the $F$ is used to generate this moment, the points of attachment must be altered appropriately (Equation 3.5). Again the test is made for the possibility of using a cervical neck strap.
\end{abstract}




\subsection{Treatment Goals}

One of the factors contributing to the observed variability in orthodontic movement of teeth is that of the lack of precision of the applied force system. Substantial benefits, then, may be gained from techniques and ideas which help the clinician to apply force systems that are precisely those which he has specified. The achievement of these benefits depends upon the willingness of the clinician to add some quantitative considerations to his normal clinical judgements. As an example, one of the ideas which call for a modified approach on the part of the clinician is that of partitioning. The clinical benefits of partitioning come directly from the fact that, where required, a sequence of simple force systems may be used to replace one complicated system. Thus, at all stages of headgear treatment the clinician is in a position to understand fully the system of forces applied and their expected effects. By the same token, monitoring of progress towards the sequential goals is readily performed, and if needed, informed modification of the force system may be made during treatment.

The precision made possible by the method of partitioning can only be fully realized if clinical judgement is the controlling factor in the feed-back process involved in performing orthodontic tooth movement.

In summary, the adoption of a quantitative and heuristic approach is essential if the principles and ideas presented here are to favora- 
bly influence the successful achievement of the goals in headgear therapy. 


\section{Conclusions}

The Review of the Literature revealed a lack of consensus amongst those presenting ideas about headgear mechanics and their application. Differences of opinion were more frequently found than were unifying ideas. In particular, asymmetric force application seems to have produced as many ideas as investigators.

It was concluded from this evidence that a fundamental study of the underlying mechanics was essential. This study revealed the need to view headgear mechanics as a three dimensional system and that failure to recognize this was one of the fundamental causes of the previous conflict of views. A further revelation came from treating the mechanical system by means of the vector algebra. In this way essential incompatibilities between many desired force systems were demonstrated and means of circumventing them were suggested.

The vector mechanics approach showed clearly that forces required for translation in many cases cannot provide the moments needed for simultaneous rotation. It was concluded that several acceptable solutions to this difficulty can be realized in practice. Where complex movements are simultaneously needed a non-elastic head band capable of supporting couples, as well as forces of translation, is proposed. In other situations where simultaneity is not called for a sequencing of treatment is suggested. Sequencing involves dividing the force system into two or three compatible systems with orthodontic judgement deciding temporal priority. The principle advantage gained from sequencing 
is that of ensuring that no spurious forces or moments are generated. A further advantage is that of knowing precisely a sequence of relatively simple force systems so that monitoring of the patient's progress is possible and practicable. A computer aid to sequencing problems is given, and an innovative solution is proposed to the unilateral distalization problem.

Analysis shows that conventional solutions generate deleterious as well as desired effects. These deleterious effects are not generated if the asymetric attachment points on the face bow are matched with appropriate asymmetry in the neck strap. This is termed a buttressed neck strap and a computer generated design of such an asymmetric headgear is shown.

The foregoing solution to a practical problem was the logical consequence from consideration of the vector analysis of the system. This illustrates the overall conclusion drawn from this work, namely, that the understanding and most effective clinical use of extra-oral force systems cannot precede a full understanding of the relevent vector mechanics. 
Bibliography

Angle, E.H. 1889. Regulationg appliances. Int. Dent. J. 10: $323-329$.

Baldini, G. 1980. Unilateral headgear: Lateral forces as unavoidable side effects. Am. J. Orthod. 77: 333-339.

Baldridge, J.P. 1953. Construction and use of unilateral headcap with report of cases. (unpublished, copy supplied by author)

Baldridge, J.P. 1961. Unilateral action with headcap. Angle Orthod. 31: $63-68$.

Barton, J.J. 1972. High-pull headgear versus cervical traction: A cephalometric comparison. Am. J. Orthod. 62: 517-529.

Block, A.J. 1962. An analysis of midline and off-center extra-oral force. Angle Orthod. 32: 19-26.

Brodie, A.G., Downs, W.B., Goldstein, A., Myer, E. 1938. Cephalometric study of orthodontic results. Angle Orthod. 8: 261-351.

Bowden, D.E.J. 1978. Theoretical considerations of headgear therapy: A literature review. Br. J. Orthod. 5: 145-152.

Brandt, S. and Root, T.L. 1975. Interview: Dr. Terrel L. Root on headgear. J. Clin. Orthod. $\underline{g}(\underline{1}): 20-31$.

Case, Calvin S. 1921. Dental Orthopedia and Correction of Cleft Palate. 2nd Ed., Chicago., C.S. Case Company. pp. 132-135.

Damon, D.H. 1970. A clinical study of extra-oral highpull traction to the maxilla utilizing a heavy force: A cephalometric analysis of dentofacial changes. MSD Thesis. University of Washington.

Drenker, E.W. 1959. Unilateral cervical traction with a Kloehn extra-oral mechanism. Angle Orthod. 29: 201-205. 
Epstein, W.N. 1948. Analysis of changes in molar relationships by means of extra-oral anchorage (head-cap) in treatment of malocclusion. Angle Orthod. 18: 63-69.

Gould, I.E. 1957. Mechanical principles in extra-oral anchorage. Am. J. Orthod. 43: 319-333.

Greenspan, R.A. 1970. Reference charts for controlled extra-oral force to maxillary molars. Am. J. Orthod. 58: 486-491.

Haack, D.C. and Weinstein, S. 1958. The mechanics of centric and eccentric cervical tractions. Am. J. Orthod. 44: 346-357.

Hershey, H.G., Houghton, C.W. and Burstone, C.J. 1981. Unilateral face bows. A theoretical and laboratory analysis. Am. J. Orthod. 79: 229-249.

Houghton, C.W. 1977. A theorectical and laboratory evaluation of unilateral face bows. M.S. Thesis. University of North Carolina.

Jacobson, A. 1979. A key to the understanding of extra-oral forces. Am. J. Orthod. 75: 361-386.

Kingsley, N.W. (1892). Adenoid growths, mouth breathing, and thumbsucking in their relation to deformities of the jaws and irregular teeth. Dental Cosmos 34: 16-22.

Kloehn, S.J. 1947. Guiding alveolar growth and eruption of the teeth to reduce treatment time and produce a more balanced denture and face. Angle Orthod. 17: 10-33.

Kloehn, S.J. 1953. Orthodontics -- force or persuasion. Angle Orthod. 23: 56-65.

Kloehn, S.J. 1955. At what age should treatment be started? Am. J. Orthod. 4I: 262-278.

Kuhn, R.J. 1968. Control of anterior vertical dimension and proper selection of extra-oral anchorage. Angle Orthod. 38: 340-349. 
Latimer, J.S. 1886. Report of discussions of the Society of Dental Surgeons of the City of New York. Dental Cosmos 8: 90-94..

Merrifield, L.L. and Cross, J.J. 1970. Directional forces. Am. J. Orthod. 57: 435-464.

Oosthuizen, L., Dijkman, J.F.P. and Evans, W.G. 1973. A mechanical appraisal of the Kloehn extra-oral assembly. Angle Orthod. 43: $221-232$.

Oppenheim, A. 1944. A possibility of physiologic orthodontic movement. Am. J. Orthod. Oral Surg. 30: 345-368.

Poulton, D.R. 1959. Changes in Class II malocclusions with and without occipital headgear therapy. Angle Orthod. 29: 34-250.

Poulton, D.R. 1967. The influence of extra-oral traction. Am. J. Orthod. 53: 8-18.

Ricketts, 1960. Influence of orthodontic treatment on facial growth and development. Angle Orthod. 30: 103-131.

Schudy, F.F. 1965. The rotation of the mandible resulting from growth: its implications in orthodontic treatment. Angle Orthod. 35: 36-50.

Schudy, F.F. 1968. The control of vertical overbite in clinical orthodontics. Angle Orthod. 38: 19-39.

Terlingen, P.J.A.M. 1973. Een materieel en een mathematisch model ter bestudering van het krachtenpatroon bij orthodontische extra-orale traktie (Material and mathematical model experiments on orthodontic extra oral tractions). Dr. M. Thesis. University of Nymegen, The Netherlands.

Wieslander, L. 1963. Effect of orthodontic treatment on the concurrent development of the craniofacial complex. Am. J. Orthod. 49: $\quad 15-27$. 
Worms, F.W., Isaacson, R.J. and Speidel, T.M. 1973. A concept and classification of centers of rotation and extra-oral force systems. Angle Orthod. 43: 384-401. 